\title{
Grain legume cultivation and children's dietary diversity in smallholder farming households in rural Ghana and Kenya
}

\author{
Ilse de Jager ${ }^{1,2}$ (1) Abdul-Razak Abizari ${ }^{3}$ - Jacob C. Douma ${ }^{4,5}$ • Ken E. Giller ${ }^{2}$. \\ Inge D. Brouwer ${ }^{1}$
}

Published online: 11 October 2017

(C) The Author(s) 2017. This article is an open access publication

\begin{abstract}
Boosting smallholder food production can potentially improve children's nutrition in rural Sub-Saharan Africa through a production-own consumption pathway and an income-food purchase pathway. Rigorously designed studies are needed to provide evidence for nutrition impact, but are often difficult to implement in agricultural projects. Within the framework of a large agricultural development project supporting legume production (N2Africa), we studied the potential to improve children's dietary diversity by comparing N2Africa and non-N2Africa households in a cross-sectional quasi-experimental design, followed by structural equation modelling (SEM) and focus group discussions in rural Ghana and Kenya. Comparing N2Africa and non-N2Africa households, we found that participating in N2Africa was not associated with improved dietary diversity of children.
\end{abstract}

Electronic supplementary material The online version of this article (https://doi.org/10.1007/s12571-017-0720-0) contains supplementary material, which is available to authorized users.

Ilse de Jager

Ilse.deJager@wur.nl

1 Division of Human Nutrition, Wageningen University, PO Box 17, 6700, AA Wageningen, The Netherlands

2 Plant Production Systems Group, Wageningen University, PO Box 430, 6700, AK Wageningen, The Netherlands

3 Department of Community Nutrition, School of Allied Health Sciences, University for Development Studies, PO Box TL 1883, Tamale, Ghana

4 Centre for Crop Systems Analysis group, Wageningen University, Droevendaalsesteeg 1, 6708, PB Wageningen, The Netherlands

5 Laboratory of Entomology, Wageningen University, PO Box 8031, 6700, EH Wageningen, The Netherlands
However, for soybean, SEM indicated a relatively good fit to the posteriori model in Kenya but not in Ghana, and in Kenya only the production-own consumption pathway was fully supported, with no effect through the income-food purchase pathway. Results are possibly related to differences in the food environment between the two countries, related to attribution of positive characteristics to soybean, the variety of local soybean-based dishes, being a new crop or not, women's involvement in soybean cultivation, the presence of markets, and being treated as a food or cash crop. These findings confirm the importance of the food environment for translation of enhanced crop production into improved human nutrition. This study also shows that in a situation where rigorous study designs cannot be implemented, SEM is a useful option to analyse whether agriculture projects have the potential to improve nutrition.

Keywords Dietary diversity $\cdot$ Legume production $\cdot$ SEM analysis $\cdot$ Children $\cdot$ Ghana $\cdot$ Kenya

\section{Introduction}

Over two billion people suffer from multiple micronutrient deficiencies worldwide, with high prevalence among young children in sub-Saharan Africa (Muthayya et al. 2013). More than one in three children under five years of age in sub-Saharan Africa are stunted (UNICEF et al. 2015). The majority of malnourished people live in rural areas and depend on agriculture as an important source of the food and income required for their nutrition and health (Pinstrup-Andersen 2012). Agricultural interventions therefore have great potential to improve nutrition, but this potential is yet to be unleashed (Ruel and Alderman 2013). There is a strong call for evidence to 
support this, based on rigorous research (Masset et al. 2012).

Boosting the production of grain legumes by smallholder farmers is a feasible option to improve nutrition in rural areas. The advantage of grain legumes like cowpea, groundnut and soybean is twofold. First, legumes are unique in that they can fix nitrogen from the air in symbiosis with Rhizobium bacteria, increasing their production and enhancing soil fertility, thus increasing the production of other crops (Giller et al. 2013). Second, compared with maize, which is the most commonly produced and consumed staple in sub-Saharan Africa, legumes are better sources of high quality protein and contain a larger variety and greater concentration of micronutrients (de Jager 2013; FAO et al. 2012; Lukmanji et al. 2008).

Many agricultural interventions aim to increase food production from one or several crop(s) and assume this will result in improved nutrition outcomes. Literature describes many different potential pathways through which agricultural projects may affect nutrition outcomes positively, but also negatively (Du et al. 2015; Hoddinott 2011; Herforth and Harris 2014). The main pathways identified are: crop production for own consumption (the production-own consumption pathway), crop production for income used to purchase food (the income-food purchase pathway) and improvement of women's status in crop production and nutrition (the women's empowerment pathway). The production-own consumption pathway assumes that increased production of nutritious foods increases consumption of these foods and adds to diversity of the household's diet (Du et al. 2015; Masset et al. 2012). Greater dietary diversity results in improved nutrient adequacy of the diet, which is especially important for vulnerable groups like young children (Kennedy et al. 2007; Moursi et al. 2008). Increased legume production may lead to increased consumption of legumes, adding to dietary intake of energy, proteins, minerals and B vitamins, and improved dietary diversity. In Malawi, for example, an agriculture and nutrition education project offering different legume intercrops (including groundnut and soybean) to farmers, resulted in increased cultivation of legumes, increased the frequency of legume consumption by children and improved their nutritional status in villages that were most intensely or longest involved in the project (Bezner Kerr et al. 2007; Bezner Kerr et al. 2010). The authors did not report on the impact on children's dietary diversity. The income-food purchase pathway assumes that increased agricultural income through increased production is used for immediate or future household needs, including food and non-food purchases to support improved nutrition outcomes such as dietary diversity ( $\mathrm{Du}$ et al. 2015). Results of studies on effects of increased income on dietary intake are inconsistent and vary per country (Keats and Wiggins 2014). Some studies found positive effects (Muhammad et al. 2011; Monteiro 2009) and others found no effects (World Bank 2007; Masset et al. 2012) or suggested negative effects as diets tend to shift from cereals and tubers to meat, fats and sugar (Keats and Wiggins 2014). The women's empowerment pathway is a cross-cutting pathway interacting with the production-own consumption and the income-food purchase pathways. Women's status in the household is often related to children's dietary intake, as found in a study in Northern Ghana by Malapit and Quisumbing (2015). In the case of increased legume production, a greater status of women may lead to increased control over resources related to legume production and more income from the sale of legume produce. In turn, women's greater control over resources may result in the channelling of nutritious foods within households to the advantage of children, and to more income spent on nutritious food and health care, particularly for children (Smith et al. 2003; UNICEF 2011). However, the increase of female participation in agriculture may trade off with time spent on care practices, negatively influencing child nutrition (Barrios 2012; Cunningham et al. 2015).

The food environment, defined as the "collective physical, economic, policy, and socio-cultural surroundings, opportunities, and conditions that influence people's food and beverage choices" (Swinburn et al. 2015), is at the interface between food production and dietary intake, and includes the availability, affordability, convenience and desirability of various foods. For example, the effect of increased legume production on children's dietary diversity may depend on the household's landholding influencing all three pathways. The landholding of households is associated with the quantity of household crop production and the household's agricultural income (Mather 2009). However, the food environment is often not measured in agriculture-nutrition evaluations (Herforth and Ahmed 2015). To better understand the effect of boosting food production on children's dietary diversity, quantitative assessments of the production-own consumption and the incomefood purchase pathways are needed, while taking into account the role of women and the food environment.

More rigorous and better designed studies are needed in agriculture and nutrition evaluations (Masset et al. 2012) but these have methodological challenges such as with establishing proper comparison groups, lacking baseline data and matching the project implementation process with rigorous study designs (Menon et al. 2013). A mixed methods design is used more frequently in project evaluations as the triangulation of complementary methods may add more rigour in evaluations (Creswell and Plano Clark 2011). Structural equation modelling (SEM) compares alternative models to assess relative model fit and is a powerful robust method for modelling complex causal paths taken by mediating variables (Garson 2015). SEM has not been used in agriculture and nutrition evaluations and may be a relevant additional method to analyse the complex pathways in this field. 
We studied the potential of increased household legume production to improve the dietary diversity of children in two different sub-Saharan African rural settings, Ghana and Kenya, by using a convergent parallel mixed method design (Creswell and Plano Clark 2011) to explore and differentiate the productionown consumption pathway and the income-food purchase pathway. First, we compared children's dietary diversity of households that did or did not participate in an agricultural intervention boosting legume production, using a cross-sectional quasiexperimental study design. Second, we studied the direction, the strength and the relative importance of the production-own consumption and the income-food purchase pathways to acquire insight in how an agricultural intervention may improve children's dietary diversity. We qualitatively studied these pathways through focus group discussions, as well as explored the potential of assessing these pathways through the quantitative method of structural equation modelling.

\section{Materials and methods}

\subsection{Study areas}

The study was carried out in Northern Ghana and in Western Kenya with widely contrasting agro-ecological characteristics. Northern Ghana has one cropping season per year of 5 to 6 months starting in May, an average annual temperature of $28^{\circ} \mathrm{C}$ and annual rainfall of 900 to $1040 \mathrm{~mm}$. The main crops are maize, rice, sorghum, pearl millet, soybean, cowpea, groundnut and yam. Travel time to urban markets is between $1 \mathrm{to} 7 \mathrm{~h}$ and human population density is sparse with 50 to 100 inhabitants per $\mathrm{km}^{2}$ (Franke et al. 2011). Western Kenya has a short cropping season of 3 months from October and a long season lasting 6 months from March, an average annual temperature of $21^{\circ} \mathrm{C}$ and annual rainfall of 1350 to $1800 \mathrm{~mm}$. The main crops are maize, pearl millet, groundnut, tea, beans, cassava and sweet potato. Travel time to urban markets is between 1 and $5 \mathrm{~h}$ and population is dense with 300 to 1200 inhabitants per $\mathrm{km}^{2}$ (Franke et al. 2011). This study was carried out in Karaga district in Northern Region and Bawku West district in Upper East Region in Ghana, and in Western province and Nyanza province in Kenya. These two contrasting locations in Ghana and Kenya were selected because, among the N2Africa project (see next sub-section) locations in these countries, they differed most in agro-ecological characteristics and therefore were assumed to best represent Northern Ghana and Western Kenya.

\subsection{N2Africa intervention}

The study was conducted in the context of an agricultural intervention designed to boost grain legume production, the N2Africa project. N2Africa is a large scale development-to- research project that aims to enable smallholder African farmers to benefit from symbiotic nitrogen fixation by grain legumes through effective production technologies (Giller et al. 2013). Phase I of N2Africa was implemented in Ghana and Kenya from 2009 to 2013 and during that period N2Africa was not designed to be nutrition-sensitive.

Each farmer participating in N2Africa received once a package with seed of an improved legume variety, triple superphosphate (TSP) fertilizer, and in cases where soybean seeds were provided, they also received rhizobia inoculant. Each cropping season from 2009 to 2013 different farmers received a package (18000 and 20000 packages in 2010, 32000 and 55000 in 2011, 75000 and 85000 in 2012 and 2013 in Ghana and Kenya, respectively) (Woomer et al. 2014). In Ghana, farmers received improved seeds of cowpea, groundnut or soybean and in Kenya farmers received improved seeds of soybean or climbing bean. Farmers tested the package on their own fields, with different treatments of seed and fertilizer on sub-plots. In the case of cowpea and groundnut the two treatments included no inputs (control) and with TSP (treatment) for two different varieties. In case of soybean, the four treatments included no inputs (control), with TSP, with inoculants, and with both TSP and inoculants. N2Africa was implemented through groups of farmers of 30 people (in Ghana) and 20-25 people (in Kenya), consisting of a 'lead' farmer who was trained in crop management practices directly by N2Africa and 'satellite' farmers who were trained by the lead farmer. In Kenya, some satellite farmers received the package twice and were referred to as 'progressive' farmers. Lead farmers had try-outs of $20 \times 30 \mathrm{~m}$ with four sub-plots of $10 \times 15 \mathrm{~m}$ and 'satellite' farmers had try-outs of $20 \times 20 \mathrm{~m}$ with four sub-plots of $10 \times 10 \mathrm{~m}$. Training on processing of legumes, especially soybean, was received by some of the female farmers. These activities were numerous and diverse across eight N2Africa countries and due to the scale of the operation could not be systematically monitored (Woomer et al. 2014).

The training and the testing of different legume technologies on farmer's own fields aimed to motivate farmers to subsequently adopt technologies, thereby increasing both their land under legume cultivation and legume productivity, resulting in increased legume production. In a study carried out among N2Africa participants in 2013, the majority of N2Africa participants reported an increase in legume area cultivated, in legume production and in input use compared with four years ago prior to the N2Africa intervention (Stadler et al. 2016). In Kenya, $52 \%$ reported an increase in soybean area cultivated, $81 \%$ reported an increase in soybean production and $9 \%$ reported using inoculants, $16 \% \mathrm{P}$ fertilizer or blend and $61 \%$ both inputs (input value chains are most advanced in Kenya) after the N2Africa intervention. In Ghana, farmers reported an increase in area under soybean, cowpea and groundnut cultivation of $42 \%, 36 \%$ and $30 \%$, respectively, 
and reported an increase in soybean, cowpea and groundnut production of $61 \%, 62 \%$ and $37 \%$, respectively. Furthermore, in the case of soybean, $6 \%$ reported using inoculants, $19 \% \mathrm{P}$ fertilizer or blend and $6 \%$ both inputs after the N2Africa intervention. For cowpea, $10 \%$ reported using $\mathrm{P}$ fertilizer or blend, and for groundnut, $15 \%$ reported using $\mathrm{P}$ fertilizer or blend after the N2Africa intervention (Stadler et al. 2016). Farmer field trials showed that the average increase in soybean, cowpea and groundnut yield after N2Africa was $350 \mathrm{~kg} /$ ha, $100 \mathrm{~kg} / \mathrm{ha}$ and $100 \mathrm{~kg} / \mathrm{ha}$, respectively. In the case of full adoption of N2Africa practices (i.e., use of improved seeds, TSP fertilizer and, in the case of soybean, inoculants), the average increase in soybean, cowpea and groundnut yield was $800 \mathrm{~kg} / \mathrm{ha}, 450 \mathrm{~kg} / \mathrm{ha}$ and $200 \mathrm{~kg} / \mathrm{ha}$, respectively (Woomer et al. 2014).

\subsection{Cross-sectional quasi-experimental study and structural equation modelling}

\subsubsection{Subject selection}

For the cross-sectional quasi-experimental study, infants and young children (6 to 59 months old) from households that participated in the N2Africa project (N2Africa group) and from households that did not participate in N2Africa (nonN2Africa group) were included (Fig. 1). A sample size of 400 (200/group), taking into account that $15 \%$ of households may refuse to take part in this study, was estimated to be sufficient to detect a difference in height-for-age z-scores (HAZs) of rural Ghanaian and Kenyan children (6 to 59 months old) of 0.4 and assuming an SD of 1.5 HAZ (District Monitoring and Evaluation Team Ghana et al. 1999-2001), at a 5\% significance level with $80 \%$ power. Reliable estimates of expected differences in children's dietary diversity and its distribution were not available, therefore HAZ was used as the outcome measure for the sample size calculation.

Households were included that had recently participated in N2Africa prior to data collection. For the N2Africa group in Ghana, households were randomly selected from those that received inputs from N2Africa in 2012. These were from villages that had participated in N2Africa since 2010. In Ghana, each village is linked to an agricultural extension agent and each agent has more villages under his or her supervision. For the non-N2Africa group in Ghana, all villages were selected that were under supervision of the same agricultural extension agent as the selected N2Africa villages but that did not participate in N2Africa. From these villages, households were selected by the random walk method (UN 2005). For each agricultural extension agent, the same number of households were selected for the non-N2Africa group as for the N2Africa group. For the N2Africa group in Kenya, households were randomly selected from those that received soybean inputs from N2Africa in the short rainy season in 2010 and in the long rainy season in 2011. For the non-N2Africa group in Kenya, households were randomly selected among those that received N2Africa soybean inputs in the short rainy season in 2013 but had no harvest yet at the time of data collection. In both countries, households were included when a child of 6 59 months of age (if more than one was present, one was selected at random), mother or caregiver of the selected child and N2Africa farmer (N2Africa group) or household head (non-N2Africa group) were present. Households that did not meet these criteria were replaced randomly. For the SEM, data from the children and their households in the N2Africa and non-N2Africa group selected for the cross-sectional quasi-experimental study were combined.

\subsubsection{Data collection}

Data were collected in the lean season in Ghana in March 2013 and in Kenya in November and December 2013 by trained interviewers who spoke the local language. Informed consent was obtained from the N2Africa farmers (N2Africa group) or household heads (non-N2Africa group).

Household characteristics and legume production A structured questionnaire-based interview was conducted. The N2Africa farmer (N2Africa group) or household head (nonN2Africa group) from the household of the selected child was interviewed to collect information on household composition, education, landholding, livestock ownership, assets, sources of income, labour hired-in (whether other people work on the household's field(s), for cash or in kind), labour hired-out (whether household members work on other people's field(s), for cash or in kind). Livestock assets recorded included cattle, donkey, pig, sheep, goat, chicken, guinea fowl, duck and dove. Tropical Livestock Unit conversion factors defined as a mature animal weighing $250 \mathrm{~kg}$ (Jahnke 1982) were used to calculate total livestock value in Tropical Livestock Units (TLU) in each household. Household assets included availability of a functioning radio, television, bicycle, motor, corn mill, private and/or commercial vehicle. The total value of assets in each household was calculated by the summed proportion of local market value of each available asset relative to the most expensive asset locally available. Total production of all legume crops from the previous year was recorded in local units together with the quantity used for home consumption, sold, and for other uses. Conversion factors were collected to convert local weight units to $\mathrm{kg}$. In addition, specific information on participation in N2Africa was collected and also whether other legumes or legume-related and nutrition-related interventions provided outside of N2Africa were received during the last four years. The mother or caregiver of the selected child was interviewed on the child's age and sex; and the mother's age, education, occupation and religion. 
Fig. 1 Flow chart of sample selection for the cross-sectional quasi-experimental study in Ghana a and Kenya b.

$\mathrm{N} 2 \mathrm{Africa}=$ is an agricultural project focused on putting nitrogen fixation to work for smallholder farmers growing legume crops in Africa. No. = number. AEA $=$ agricultural extension agent. 'Central node' = action site of N2Africa that covers both Western and Nyanza province in Kenya. Short rain $=$ short cropping season of 3 months from October in Western Kenya. Long rain = long cropping season lasting 6 months from March in Western Kenya. Co-operators $=$ local partners implementing N2Africa project
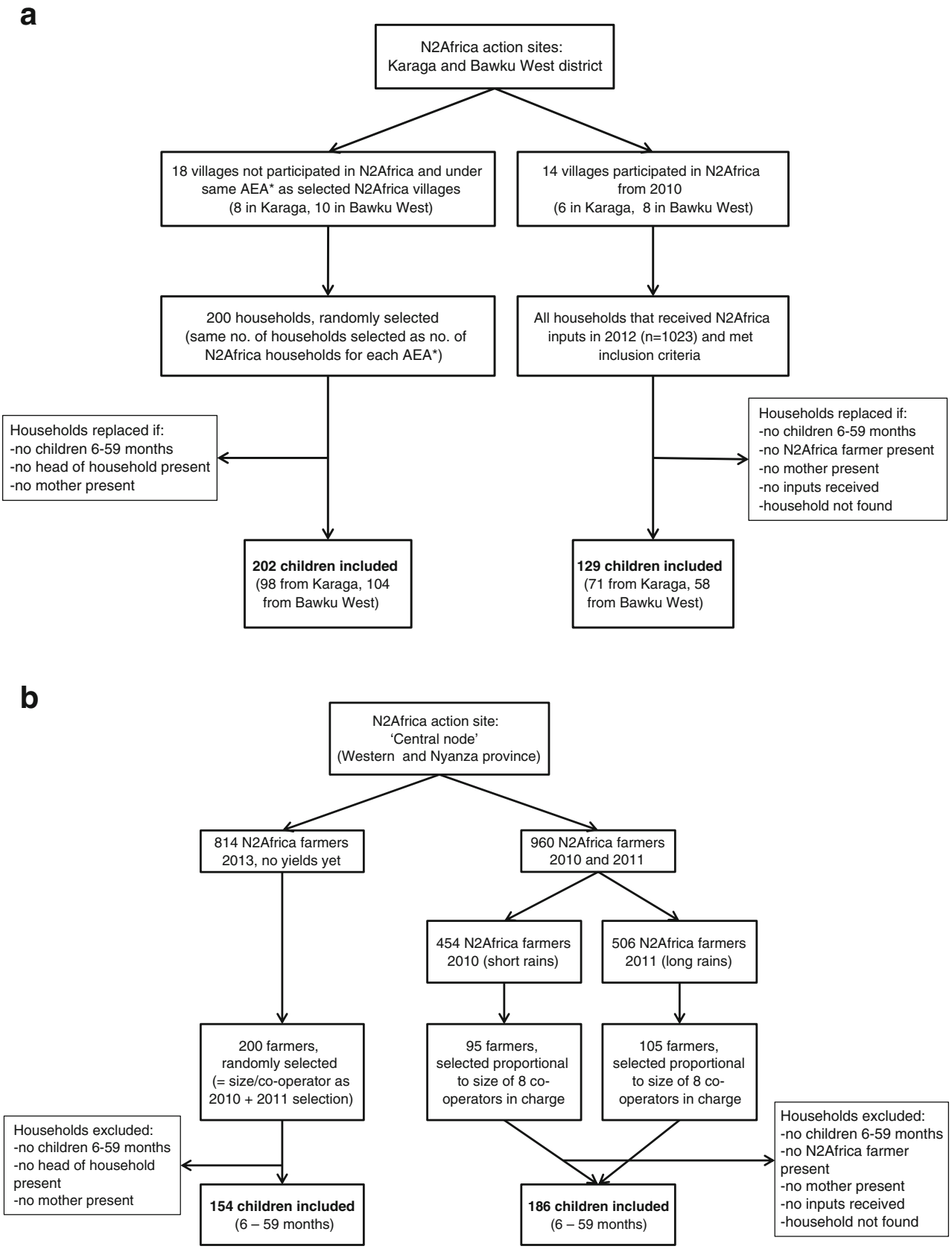

Children's legume consumption and dietary diversity A short food frequency questionnaire was administered to mothers or caregivers to collect data on the frequency of consumption of different legumes (groundnut, cowpea, soybean, Bambara groundnut, pigeon pea, climbing bean, kidney bean and mungbean) by children during the last month. Through a qualitative multi-pass 24-h-recall method (Gibson and Ferguson 2008; FAO 2010), mothers or caregivers were asked to mention all foods and beverages their child had consumed during the preceding 24-h (wakeup-to-wakeup) including anything consumed outside the home. After probing for likely-to-be-forgotten foods such as snacks and fruits, they were asked to give detailed descriptions of the foods and beverages consumed, including ingredients for mixed dishes. The 24-h-recall data were used to calculate an Individual Dietary Diversity Score (IDDS) (FAO 2010), being a count of the number of food groups consumed. Consumption of any amount of food from each food group was sufficient to 'count', except if an item was used as a condiment. We used the seven food groups recommended by WHO et al. (2007) that were validated to reflect nutrient adequacy of children aged 6-23 months. The seven groups included: (1) grains, roots and/or tubers; (2) legumes and/or nuts; (3) dairy products; (4) flesh foods; (5) eggs; (6) vitamin A rich fruits and/or 
vegetables; and (7) other fruits and/or vegetables (WHO et al. 2007). Fruits and vegetables were classified as vitamin-A rich when they provided 60 retinol activity equivalents (RAE) per $100 \mathrm{~g}$ or more (FAO 2010), using the Tanzania Food Composition data base (Lukmanji et al. 2008) for Kenya and the Mali (Barikmo et al. 2004) and West African Food Composition data base (FAO et al. 2012) for Ghana. Consumption of four or more food groups out of these seven is associated with better quality diets of infants and young children of 6-23 months (Working Group on Infant and Young Child Feeding Indicators 2007). Mean IDDS was calculated for all children and separately for children aged 623 months and children of 24-59 months. For children of 623 months, the proportion of children who had a nutrient diverse diet $($ IDDS $=>4)$ was calculated.

Children's nutritional status Weight and length or height of children were measured following standard procedures (Cogill 2003). Weight was measured with an electronic scale to the nearest $0.1 \mathrm{~kg}$ (UNIscale: Seca GmbH, Hamburg, Germany). Height and length was measured with a UNICEF wooden three piece measuring board with a sliding foot or head piece and with a precision of $0.1 \mathrm{~cm}$. Children below 24 months old or who were not able to stand were measured lying down (length). Children aged 24-59 months were measured standing up (height). Both length/height and weight were measured twice for each child and the average of the two measurements was taken. Scales were calibrated with a standard weight each day of data collection. Age was calculated using the date of birth from verifiable documents (health record, weighing card, birth certificate) or estimated based on a traditional calendar or another record (29 children in Ghana and 36 children in Kenya) and the date of the survey. Height and weight measurements were converted into height-for-age, weight-for-height and weight-for-age z-scores using the WHO Child Growth Standards (WHO Multicentre Growth Reference Study Group 2006) by using the WHO SPSS syntax (WHO 2011). Children who were more than two standard deviations below the reference median of height-for-age, weight-for-height and weight-for-age z-scores were classified to be stunted, wasted and underweight, respectively.

\subsection{Focus group discussions}

Both in Ghana and in Kenya, eight focus group discussions were held, four among female farmers and four among male farmers who participated in the N2Africa project. The discussions were held close to the homes of selected participants and lasted between 1 and $2 \mathrm{~h}$. The discussion was led by a researcher and supported by a trained local translator. Qualitative in-depth information was collected on the production-own consumption and income-food purchase pathways for grain legume production (with a focus on soybean) (Fig. 2). The theoretical pathways were used as a topic guide for the discussions. We recorded all discussions and translated and transcribed all the records into English.

\subsection{Ethical considerations}

The study was not subjected to review by a Research Ethics Board. It was part of a development project where participants were included based on implementer preferences and the willingness of participants to participate and did not include random allocation to either the intervention or control group. Approval for the study was obtained from the District Assembly, District Ministry of Agriculture offices and leaders of selected communities. Participation was voluntary and written informed consent was obtained from caregivers of selected children, with thumb prints used for those who were not literate. The identity of the infants and their mothers/ caregivers has been kept confidential.

\subsection{Statistical analysis}

Statistical analyses were performed using SPSS (IBM SPSS Statistics 22). Data were checked for normality by visual inspection of histograms and Q-Q plots. Non-normal data were log- or square root-transformed to approach normality. Accordingly, geometric means with $95 \%$ confidence intervals (CI) are presented. Two approaches were used to study the potential effect of enhanced grain legume production. First, univariate statistics were applied to test for differences in the characteristics between the non-N2Africa and N2Africa groups. Second, to explore interdependencies of the variables under study, the data of both the non-N2Africa and N2Africa group combined were used for SEM.

Differences in characteristics between the non-N2Africa and N2Africa groups were analysed with independent T-test (for continuous data), and Chi-Square test (for categorical data) using a post hoc test (adjusted standardized residuals and Bonferroni correction (Beasley and Schumacker 1995)) where the independent variable had more than two categories. Twosided $P<0.05$ was regarded as statistically significant.

To quantify and disentangle the various pathways from legume production to children's dietary diversity, SEM (Garson 2015) was used for data on soybean production (targeted by N2Africa in both countries). Path analysis is a technique to explicitly test multivariate causal relations between variables. It tests the likelihood of observing the data given a set of causal relations between household characteristics and the children's dietary diversity. We posited that through the production-own consumption pathway enhanced soybean production in the household $(\mathrm{kg})$ would result in an increased quantity of soybean produce used for home consumption $(\mathrm{kg})$. In turn, an increased quantity of soybean produce used for home consumption should result in increased 
a

(e)

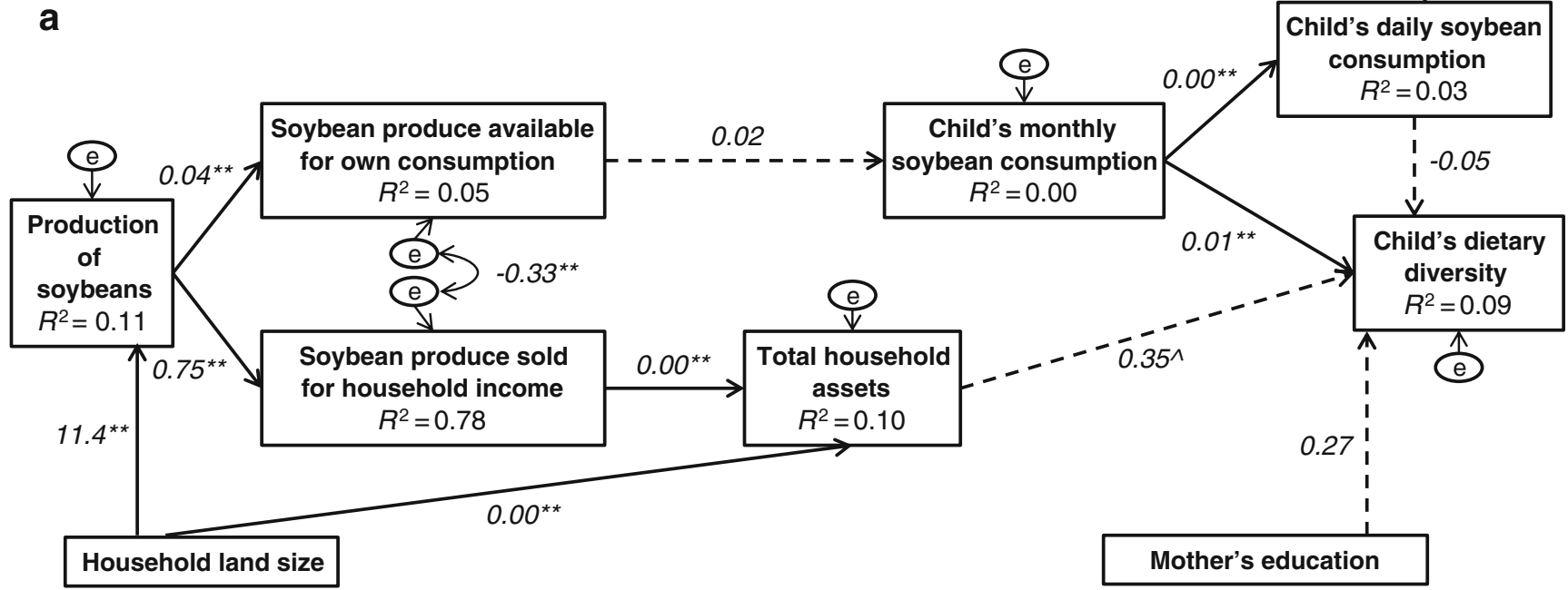

b
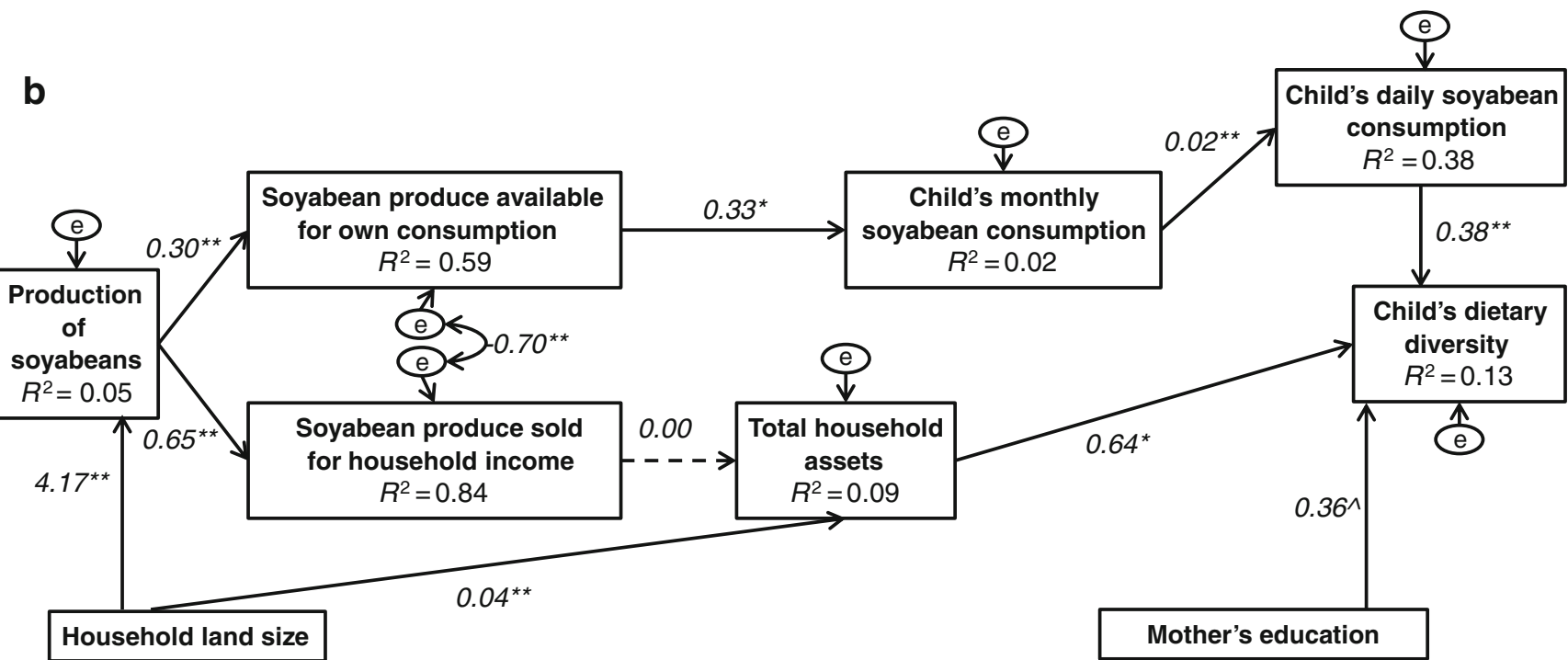

Fig. 2 Explorative structural equation model of the effect of soybean production on dietary diversity of children 6-59 months of age through the production-own consumption pathway and income-food purchase pathway in rural Northern Ghana $(n=260)$ a and in rural Westerm Kenya $(n=197)$ b. Ghana a: $X^{2}(\mathrm{df})=62.13(24), P=0.00$ and Kenya b: $\mathrm{X}^{2}(\mathrm{df})=22.59(24), P=0.64$ (corrected with Bollen-stine bootstrap). Values are unstandardized regression coefficients $\left({ }^{\wedge} P<0.10, * P<0.05\right.$, $* * P<0.01$, path coefficients not significantly different from zero are

children's monthly soybean consumption (times per month), increasing children's daily consumption (times per day) of soybean and enhancing children's dietary diversity (IDDS with range of 0 to 7 food groups). In addition, children's daily soybean consumption (times per day) should positively affect IDDS. We posited that through the income-food purchase pathway, enhanced soybean production in the household $(\mathrm{kg})$ results in an increased quantity of soybean produce sold $(\mathrm{kg})$, increased quantity of soybean produce sold results in increased income (total value of household assets), and shown by broken lines). Value between error terms of soybean yield available for own consumption and for household income is the estimated correlation. Part of the variance explained by the model (R2) is given under the variable names. ' $\mathrm{e}$ ' is the unexplained variation. Appendix 2 shows cases excluded. Appendix 3 specifies indicators used in model. Appendix 4 and 5 provide the co-variance matrix for Fig. $2 a$ and $2 b$, respectively

increased income results in improved children's dietary diversity (IDDS with range of 0 to 7 food groups). Further, we hypothesized that the quantity of soybean produce used for home consumption depends on quantity of soybean produce sold and vice versa. We also hypothesized that larger household land size (ha) results in more soybean production, thereby affecting both pathways. Finally, we posited that enhanced women's status (mother's education, low or high level) will result in improved children's dietary diversity (Fig. 2). Studies show that mother's schooling reduces the risk of stunted 

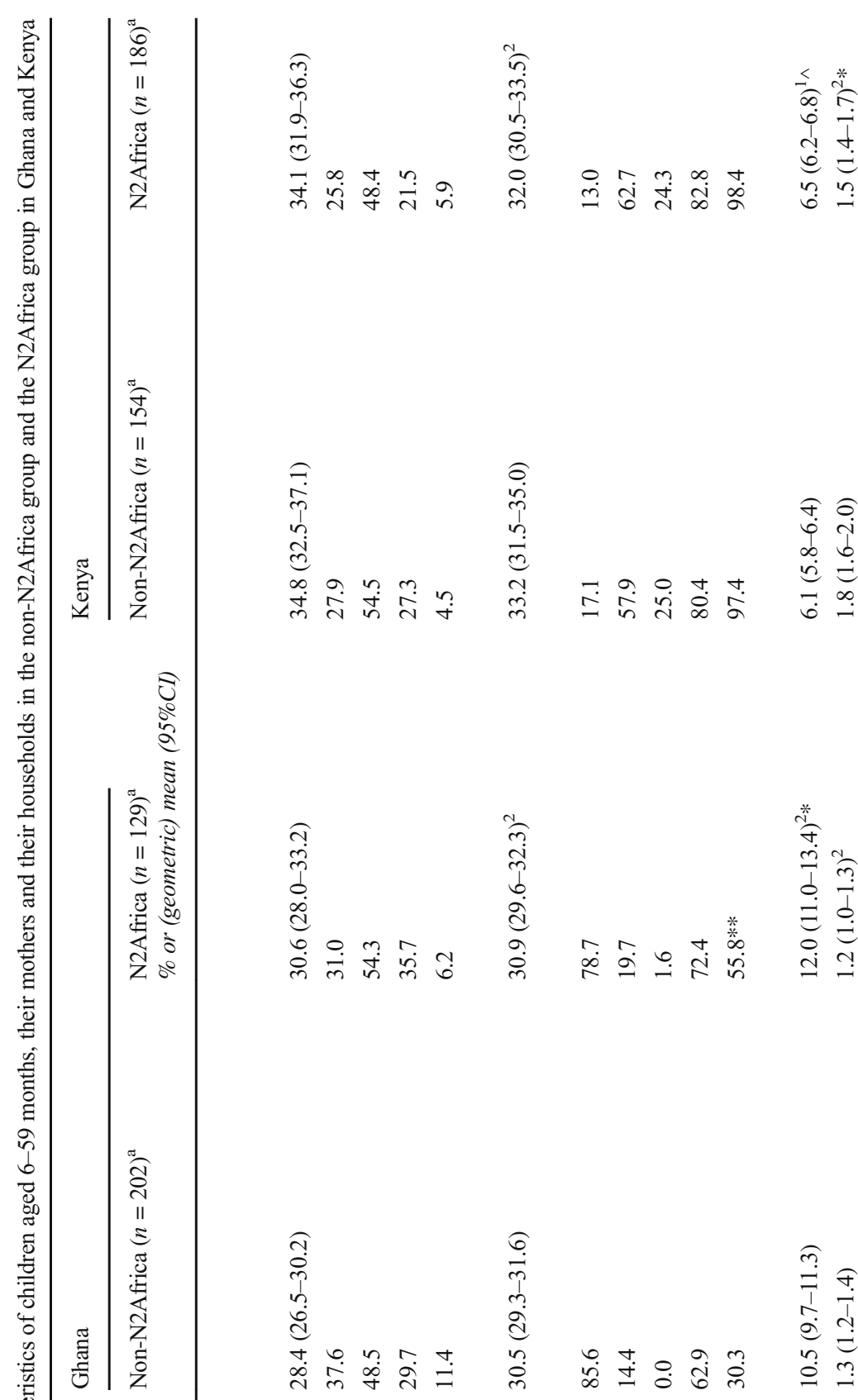

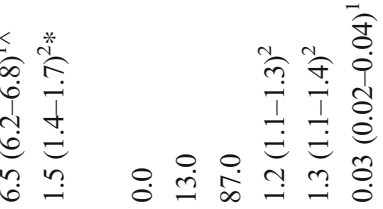

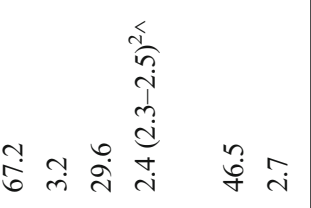

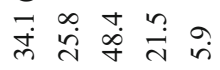

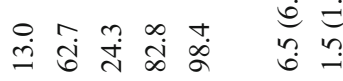

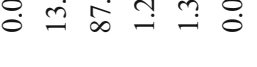

(1) (1)

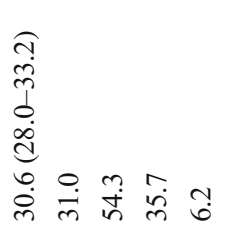

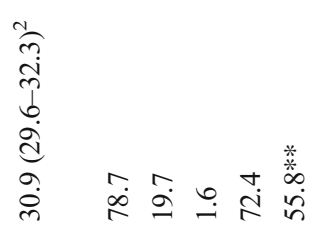

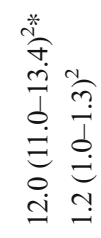

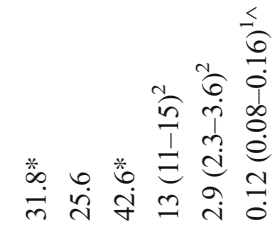

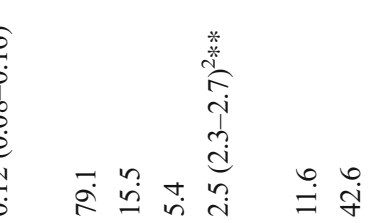

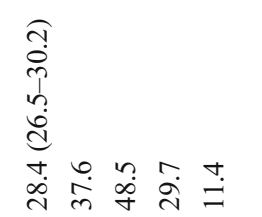

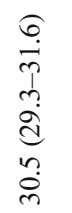

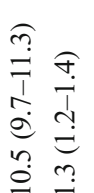

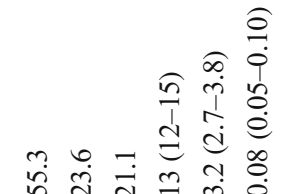

$\stackrel{\substack{0 \\ 0}}{0}$

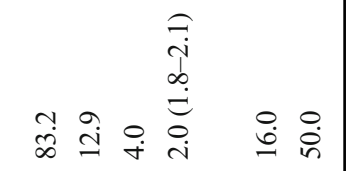

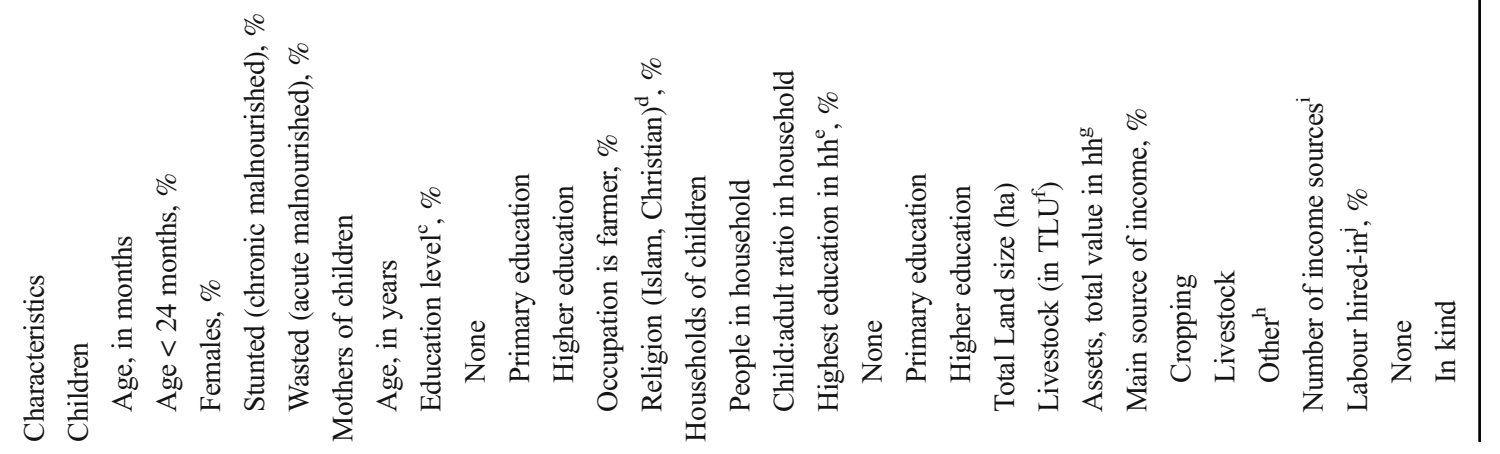




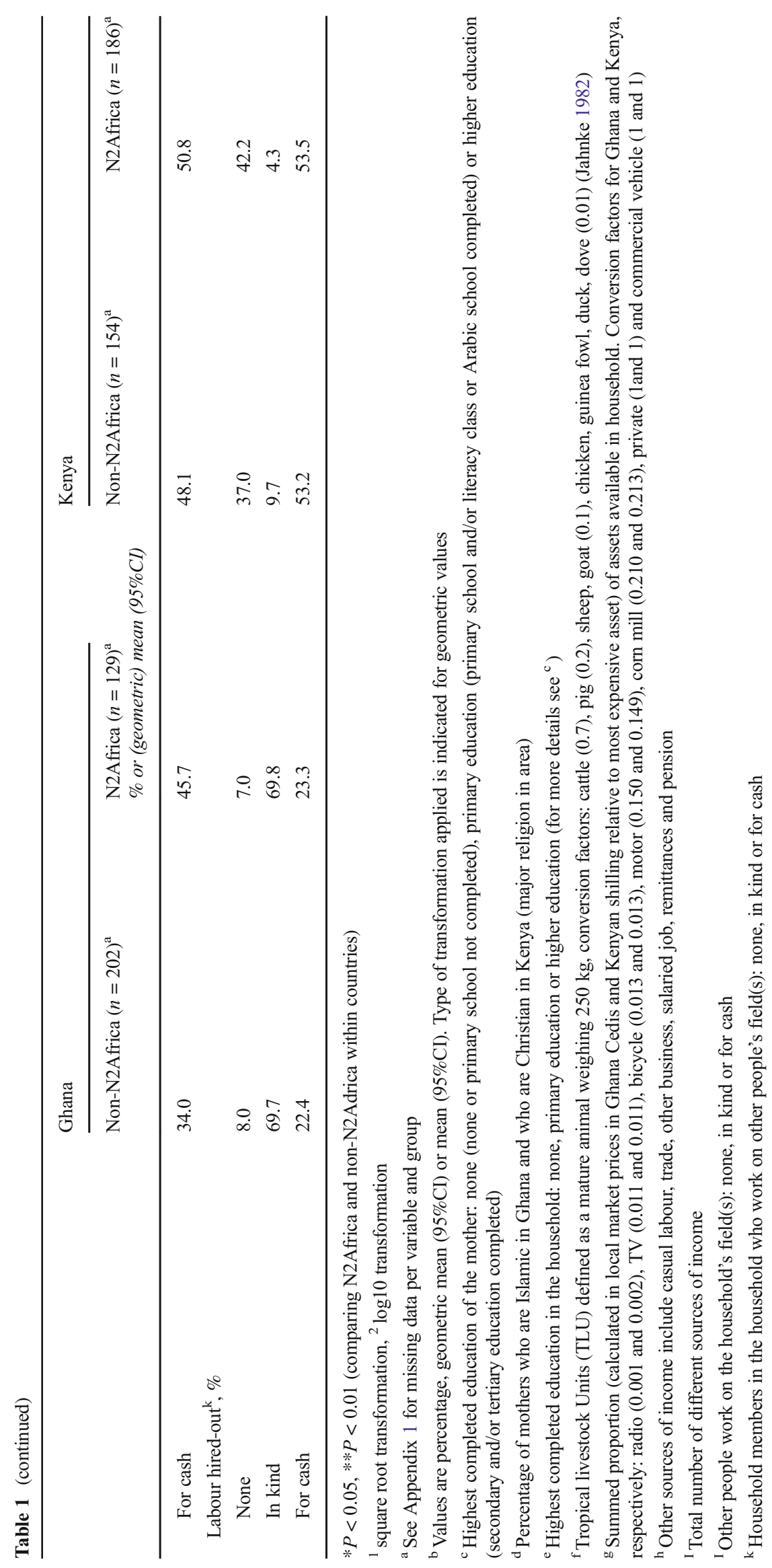


children (Ruel and Alderman 2013) and therefore education is often used as an indirect measure of women's status. The degree of fit of the hypothesized models to the data was measured by comparing the observed and measured covariance matrices. To account for non-normality of the data, a bootstrap derived chi-square statistic was used (Bollen-Stine bootstrap; 2000 samples). Lack of significant fit $(P>0.05)$ means that the hypothesized model is rejected as a causal explanation of the data. All individual relationships were tested for significance using $z$ statistics. The SEM was performed using AMOS, an add-on module for SPSS (IBM SPSS Amos 23.0.0).

All transcripts from the focus group discussions were read thoroughly several times, focusing on one theme (one of the steps in the pathways), at a time. Key words and phrases were underlined, categorized per theme and separated for women and men participants. Given the objective of this study, the convergence and inconsistencies per theme were classified. This thematic analysis gave insight into which steps of the pathways were or were not present and which factors influenced the absence of steps, according to most participants.

\section{Results}

\subsection{Characteristics of children, their mothers and households}

In Ghana, 202 versus 126 children, and in Kenya 154 versus 186 children, were included in the non-N2Africa group and the N2Africa group, respectively (Fig. 1). Characteristics of the children, their mothers and households in the nonN2Africa and N2Africa groups were comparable in both countries (Table 1). Ghanaian children were on average 29 months old and Kenyan children 34 months old, with about half being female in both countries. In Ghana and Kenya, the percentage of stunted and wasted children in the nonN2Africa and N2Africa groups did not differ. Chronic and acute malnutrition were more prevalent among Ghanaian children than Kenyan children (32\% versus $24 \%$ stunted children and $9.4 \%$ versus $5.3 \%$ wasted children, respectively, $P<0.05)$. In both countries the majority of the mothers of the selected children were farmers. In Ghana more mothers had no education compared with Kenyan mothers ( $83 \%$ versus $15 \%, P<0.05)$. In Ghana, but not in Kenya, we found more Muslim mothers (55.8\% versus $30.3 \%$ ) in the N2Africa group compared with the non-N2Africa group. Ghanaian households were comprised of more household members than Kenyan households (11.1 (10.4-11.8) versus 6.2 (6.0-6.4), respectively, $P<0.05)$. In Ghana but not in Kenya, households were larger (12.0 versus 10.5 household members) in the N2Africa group compared with the non-N2Africa group. Also in Kenya but not in Ghana, the child-to-adult ratio was smaller (1.5 versus 1.8) in the N2Africa compared with the non-N2Africa group. Ghanaian households owned about ten times more land than the Kenyan households (13 (12-14) ha versus $1.3(1.2-1.4)$ ha, $P<0.05)$. In Ghana but not in Kenya, there were more households with at least one household member who had completed a higher level of education $(42.6 \%$ versus $21.1 \%$ ) and households had more varied sources of income (2.5 versus 2.0) in the N2Africa compared with the non-N2Africa group.

\subsection{Participation in N2Africa and other interventions}

Of all N2Africa farmers included in this study, $77.3 \%$ were satellite farmers and $22.7 \%$ were lead farmers in Ghana while 48.9\% were satellite farmers, $50.0 \%$ were 'progressive' farmers and $1.1 \%$ were lead farmers in Kenya. In Ghana $39.5 \%$ and in Kenya $71.0 \%$ of the participants were female. In Ghana most of the farmers received soybean (74.4\%), some cowpea $(25.6 \%)$ and a few groundnut $(2.3 \%)$ seeds. More than half of farmers reported to have received fertilizer $(60.5 \%)$ and about half of farmers who reported to have received soybean seeds said they also received inoculant (38\%). In Kenya, all farmers reported to have received soybean seeds and almost all also reported to have received fertilizer $(92.9 \%)$ and inoculant (91.3\%). In both Ghana and Kenya, it was reported that others in their household had received support from N2Africa in the same and/or previous season, respectively $29.5 \%$ and $37.7 \%$. In Ghana $96.1 \%$ and in Kenya $44 \%$ of all farmers reported to have received training from N2Africa in crop management practices and/or training on soybean processing. In Ghana, the training received was mainly related to management practices while in Kenya training was mainly on soybean processing.

Subjects from the non-N2Africa and N2Africa groups reported to have received other legume, legume-related, (human) nutrition and/or nutrition-related interventions provided outside of N2Africa during the last four years. In Ghana and in Kenya, the number of subjects from the non-N2Africa and N2Africa group that reported to have received nutrition and nutritionrelated education received outside of N2Africa did not differ (11.4\% and $7.4 \%$ in Ghana, $2.6 \%$ and $1.1 \%$ in Kenya). In Ghana but not in Kenya, more subjects from the N2Africa group reported they had received legume or legume-related interventions provided from outside of N2Africa compared with the non-N2Africa group (14.8\% versus $5.9 \%$ ).

\subsection{Household legume production}

In Ghana and in Kenya, the total household production of all grain legumes was comparable in the two groups (Table 2). However, the proportion of households cultivating legumes was greater in the N2Africa group compared with the nonN2Africa group (100\% versus $88.1 \%$ in Ghana and $100 \%$ 
Table 2 Cultivation of grain legumes, their total production and percentage consumed or sold ${ }^{\mathrm{a}}$ reported in the non-N2Africa group and the N2Africa group in Ghana and in Kenya

\begin{tabular}{lllll} 
Ghana & & Kenya & \\
\cline { 5 - 6 } Non-N2Africa $(n=202)^{\mathrm{b}}$ & $\begin{array}{l}\text { N2Africa }(n=129)^{\mathrm{b}} \\
\text { \% or }(\text { geometric }) \text { mean } \\
(95 \% \text { CI })^{\mathrm{c}}\end{array}$ & & Non-N2Africa $(n=154)^{\mathrm{b}}$ & N2Africa $(n=186)^{\mathrm{b}}$ \\
& & &
\end{tabular}

\section{Soybean}

\begin{tabular}{|c|c|c|c|c|}
\hline Households cultivated, $\%$ & 75.2 & $90.7 * *$ & 18.2 & $94.1 *$ \\
\hline Yield of $0^{\mathrm{d}}, \%$ & 1.3 & 2.6 & 7.1 & $1.7^{\wedge}$ \\
\hline Household production $(\mathrm{kg})^{\mathrm{e}}$ & $271(218-337)$ & $257(194-340)^{2}$ & $13(9-21)$ & $9(7-10)^{2 \wedge}$ \\
\hline Consumed $(\%)^{\mathrm{f}}$ & $15(10-20)$ & $10(6-15)^{1}$ & $64(52-76)$ & $65(60-70)$ \\
\hline Sold $(\%)^{\mathrm{f}}$ & $32(25-41)$ & $30(23-39)^{1}$ & $23(12-33)$ & $22(18-26)$ \\
\hline \multicolumn{5}{|l|}{ Cowpea } \\
\hline Households cultivated, $\%$ & 55.4 & $40.3 * *$ & 8.4 & 13.4 \\
\hline Yield of $0^{\mathrm{d}}, \%$ & 3.6 & 3.8 & 0.0 & 8.0 \\
\hline Household production $(\mathrm{kg})^{\mathrm{e}}$ & $82(63-106)$ & $73(49-109)^{2}$ & $6(3-10)$ & $5(3-8)^{2}$ \\
\hline Consumed $(\%)^{\mathrm{f}}$ & $69(62-77)$ & $52(40-64)^{*}$ & $50(28-72)$ & $73(60-87)^{\wedge}$ \\
\hline Sold $(\%)^{\mathrm{f}}$ & $24(17-31)$ & $27(16-37)$ & $20(0-40)$ & $9(2-15)$ \\
\hline \multicolumn{5}{|l|}{ Sroundnut ${ }^{\mathrm{g}}$} \\
\hline Households cultivated, $\%$ & 51.0 & 54.3 & 36.4 & 34.4 \\
\hline Yield of $0^{\mathrm{d},} \%$ & 1.9 & 1.4 & 1.8 & 6.3 \\
\hline Household production $(\mathrm{kg})^{\mathrm{e}}$ & $460(366-577)$ & $584(410-830)^{2}$ & $14(10-20)$ & $12(9-17)^{2}$ \\
\hline Consumed $(\%)^{\mathrm{f}}$ & $7(4-10)$ & $3(2-5)^{2 *}$ & $66(58-75)$ & $74(67-81)$ \\
\hline Sold $(\%)^{\mathrm{f}}$ & $51(43-59)$ & $55(45-65)$ & $22(15-30)$ & $17(10-23)$ \\
\hline \multicolumn{5}{|l|}{ ther legumes ${ }^{\mathrm{h}}$} \\
\hline Households cultivated, $\%$ & 53.5 & 46.3 & 94.2 & 90.9 \\
\hline Yield of $0^{\mathrm{d}}, \%$ & 1.9 & 0.0 & 0.7 & 0.0 \\
\hline Household production $(\mathrm{kg})^{\mathrm{e}}$ & $73(56-95)$ & $69(49-98)^{2}$ & $20(17-24)$ & $16(14-19)^{2 \wedge}$ \\
\hline Consumed $(\%)^{\mathrm{f}}$ & $76(69-83)$ & $70(58-82)$ & $66(61-70)$ & $69(65-73)$ \\
\hline Sold $(\%)^{\mathrm{f}}$ & $8(3-12)$ & $9(3-16)$ & $18(14-22)$ & $15(11-18)$ \\
\hline \multicolumn{5}{|l|}{ All legumes ${ }^{\mathrm{i}}$} \\
\hline Households cultivated, $\%^{\mathrm{h}}$ & 88.1 & $100 * *$ & 94.8 & $100 * *$ \\
\hline Yield of $0^{\mathrm{d}}, \%$ & 0.0 & $3.1^{*}$ & 0.7 & 0.0 \\
\hline Household production $(\mathrm{kg})^{\mathrm{e}}$ & $495(396-620)$ & $501(371-677)^{2}$ & $26(22-32)$ & $28(24-33)^{2}$ \\
\hline Consumed $(\%)^{\mathrm{f}}$ & $43(37-48)$ & $29(23-35)^{* *}$ & $65(61-69)$ & $65(62-69)$ \\
\hline Sold $(\%)^{\mathrm{f}}$ & $40(34-45)$ & $43(37-49)$ & $18(15-22)$ & $21(17-24)$ \\
\hline
\end{tabular}

$* P<0.05, * * P<0.01, \wedge P<0.10$ (comparing N2Africa and non-N2Adrica within countries)

${ }^{1}$ square root transformation, ${ }^{2} \log 10$ transformation

${ }^{\text {a }}$ Other uses of grain legume production include: used for seeds, given back to N2Africa, stored or unknown

${ }^{\mathrm{b}}$ See Appendix 1 for missing data per variable and group

${ }^{\mathrm{c}}$ Values are percentage, geometric mean $(95 \% \mathrm{CI})$ or mean $(95 \% \mathrm{CI})$. Type of transformation applied is indicated for geometric values

${ }^{\mathrm{d}}$ Percentage of households who cultivated soybean but had no yield

${ }^{\mathrm{e}}$ Total yield in kg of previous year reported by farmers who did cultivated specific legume, excluding cases with no yield

${ }^{\mathrm{f}}$ Mean of percentage of total yield used for home consumption or sold

${ }^{\mathrm{g}}$ Reported shelled yield in $\mathrm{kg}$ is conversed to unshelled yield by conversion factor 0.4. If not indicated yield was assumed as unshelled

${ }^{\mathrm{h}}$ Reported other legumes (not received from N2Africa) cultivated. In Ghana: pigeonpea and Bambara groundnut. In Kenya: mung bean and bush bean

${ }^{\mathrm{i}}$ All legumes cultivated per household summed

versus $94.8 \%$ in Kenya, respectively). In Ghana, less of total household legume production was used for home consumption than in Kenya (37\% versus $65 \%$ of production, $P<0.05)$. In Ghana but not in Kenya, less of total household 
Table 3 Reported times of soybean, groundnut, cowpea and other grain legumes consumed per month of children 6-59 months by their mother or care-giver in the non-N2Africa group and the N2Africa group in Ghana and in Kenya

\begin{tabular}{|c|c|c|c|c|}
\hline & \multicolumn{2}{|l|}{ Ghana } & \multicolumn{2}{|l|}{ Kenya } \\
\hline & Non-N2Africa $(n=202)$ & $\begin{array}{l}\text { N2Africa }(n=129) \\
\text { geometric mean }(95 \% C I)\end{array}$ & Non-N2Africa $(n=154)$ & N2Africa $(n=186)$ \\
\hline \multicolumn{5}{|c|}{ Legume consumption, (times/month) ${ }^{\mathrm{a}}$} \\
\hline Soybean & $30.8(25.4-36.8)$ & $30.0(23.8-36.9)^{1}$ & $5.7(4.1-7.7)$ & $7.2(5.5-9.2)^{2}$ \\
\hline Groundnut & $26.7(22.6-31.1)$ & $30.8(25.3-36.9)^{1}$ & $0.3(0.1-0.6)$ & $0.1(0.0-0.3)^{1}$ \\
\hline Cowpea & $9.5(7.9-11.4)$ & $12.6(10.3-15.3)^{2 *}$ & $\mathrm{n} / \mathrm{a}$ & $\mathrm{n} / \mathrm{a}$ \\
\hline Other legumes ${ }^{\mathrm{b}}$ & $8.9(7.2-11.0)$ & $10.0(7.8-12.7)^{2}$ & $10.0(8.7-11.5)$ & $8.9(7.6-10.5)^{2}$ \\
\hline All legumes ${ }^{\mathrm{c}}$ & $97.3(85.3-110.0)$ & $103.5(89.4-118.6)^{1}$ & $21.9(18.4-26.2)$ & $22.3(18.9-26.3)^{2}$ \\
\hline All legumes without soybean ${ }^{\mathrm{d}}$ & $58.3(50.3-66.7)$ & $65.8(56.0-76.4)^{1}$ & - & - \\
\hline
\end{tabular}

$* P<0.05, \wedge P<0.10$ (comparing N2Africa and non-N2Adrica within countries)

${ }^{1}$ square root transformation, ${ }^{2} \log 10$ transformation

${ }^{\text {a }}$ Reported times of legume consumption during the last month of a child 6-59 months of age by the mother or caregiver

${ }^{\mathrm{b}}$ Other legumes, not received from N2Africa. In Ghana: pigeonpea and Bambara groundnut. In Kenya: mung bean and bush bean

${ }^{\mathrm{c}}$ All legumes consumed summed

${ }^{\mathrm{d}}$ All legumes consumed summed without soybean in Ghana. In Ghana soybean is mostly used as a condiment

legume production was used for home consumption in the N2Africa households compared with the non-N2Africa group (29\% versus $43 \%$ ). Different results were found for the individual grain legumes. In Ghana and in Kenya, more N2Africa households cultivated soybean compared with the nonN2Africa group $(90.7 \%$ versus $75.2 \%$ and $94.1 \%$ versus $18.2 \%$, respectively) but among the farmers who grew soybean the total production of soybean and percentage used for consumption or sold did not differ between groups in both countries. In the case of cowpea, in Ghana fewer households in the N2Africa group cultivated cowpea compared with the non-N2Africa group (40.3\% versus 55.4\%) and less of the cowpea production was used for consumption (52\% versus $69 \%$ ), with no differences between groups in Kenya. Total production and percentage sold did not differ for cowpea between the non-N2Africa and N2Africa groups in Ghana and Kenya. In both Ghana and Kenya, the proportion of households that cultivated groundnut and that cultivated other legumes not received from N2Africa, their total production, and their percentage sold did not differ between the non-N2Africa and N2Africa groups. This was also the case for the percentage of production used for home consumption, except for groundnut in Ghana where fewer households used them for consumption in the N2Africa group compared with the nonN2Africa group (3\% versus 7\%).

\subsection{Children's legume consumption and dietary diversity}

In both Ghana and Kenya, children's monthly frequency of consumption of soybean, groundnut, cowpea and other legume varieties not distributed through N2Africa did not differ between the non-N2Africa and N2Africa groups, except that Ghanaian children's monthly frequency consumption of cowpea was greater in the N2Africa group than in non-N2Africa group (12.6 versus 9.8, respectively) (Table 3). Compared with Kenyan children, the monthly frequency of soybean consumption was greater among children in Ghana (30.5 (26.4 $35.0)$ versus $6.4(5.3-7.8)$ times, $P$-value $<0.05)$. However, 24-h-recall data showed that in Ghana soybean was consumed mostly as a condiment and not in large portions. After excluding condiment-consumption of soybean, the monthly frequency of consumption of all legumes by children in Ghana was still greater than in Kenya (61.1 (54.9-67.7)) versus 22.1 (19.6-24.9) times per month, respectively, $P<0.05$ ). Also the daily frequency of children's legume consumption in Ghana was greater than in Kenya (1.5 (1.3-1.7)) versus 0.3 $(0.2-0.4)$ times per day, $P<0.05)$. In Ghana but not in Kenya, the daily overall consumption of legumes by children was more frequent in the N2Africa group than in the nonN2Africa group (1.9 (1.6-2.2)) versus $1.4(1.2-1.6)$ times per day, $P<0.05$ ).

In both countries, almost all children consumed grains, roots and/or tubers $(94.6 \%$ versus $93.8 \%$ in Ghana and 99.4\% versus $99.5 \%$ in Kenya, in the non-N2Africa and N2Africa groups respectively) and fruits and vegetables (83.7\% versus $89.1 \%$ in Ghana and $100 \%$ versus $94.6 \%$ in Kenya, in the non-N2Africa and N2Africa groups) (Table 4). In Ghana and also in Kenya, the proportion of children who consumed dairy products, meat foods and eggs was similar in the non-N2Africa group compared with the N2Africa group. In Ghana (but not in Kenya), more children in the N2Africa group consumed legumes, nuts and seeds than in the non- 
Table 4 Percentage of children 6-59 months who consumed a specific food groups in the non-N2Africa group and in the N2Africa group in Ghana and in Kenya

\begin{tabular}{|c|c|c|c|c|}
\hline & \multicolumn{2}{|l|}{ Ghana } & \multicolumn{2}{|l|}{ Kenya } \\
\hline & Non-N2Africa $(n=202)$ & N2Africa $(n=129)$ & Non-N2Africa $(n=154)$ & N2Africa $(n=186)$ \\
\hline Food group & $\%$ & & & \\
\hline 1. Grain, roots and tubers & 94.6 & 93.8 & 99.4 & 99.5 \\
\hline 2. Legumes, nuts and seeds & 77.2 & $86.8^{*}$ & 40.3 & 42.5 \\
\hline 3. Dairy products & 20.3 & 20.9 & 68.8 & 67.7 \\
\hline 4. Flesh foods & 87.1 & 89.1 & 36.4 & 32.8 \\
\hline 5. Eggs & 1.5 & 0.8 & 1.9 & 2.2 \\
\hline 6. Vitamin A rich fruits and vegetables & 47.0 & $34.1 *$ & 76.6 & 76.9 \\
\hline 7. Other fruits and vegetables & 83.7 & 89.1 & 100 & $94.6^{*}$ \\
\hline Oils and fats ${ }^{\mathrm{a}}$ & 62.9 & $79.1 *$ & 97.4 & 94.1 \\
\hline
\end{tabular}

$* P<0.05$ (comparing N2Africa and non-N2Adrica within countries)

${ }^{a}$ Oils and fats are not included in individual dietary diversity score

N2Africa group (86.8\% versus $77.2 \%$, respectively) and oils and fats $(79.1 \%$ versus $62.9 \%)$, but fewer consumed fruits and vegetables rich in vitamin A (34.1\% versus $47 \%)$. In Kenya (but not in Ghana), fewer children consumed fruits and also vegetables in the N2Africa group compared with those in the non-N2Africa group (94.6\% versus $100 \%)$.

Dietary diversity of children in the non-N2Africa group and the N2Africa group did not differ (Table 5). This was also the case for children below 24 months of age, children above 24 months and children who were not breastfed. However, dietary diversity was less among breastfed children in the N2Africa households than in the non-N2Africa group (3.7 versus 4.2, respectively) in Kenya, but not in Ghana. The percentage of children who had an IDDS of 4 or above among children below 24 months (reflecting a nutrient adequate diet) was similar in the N2Africa group compared with the nonN2Africa group in Ghana $(60.0 \%$ and $65.8 \%)$ and also in Kenya (62.5\% and $76.7 \%)$.

We found no associations between demographic and socioeconomic characteristics of households (household's highest completed education level, mother's education level, household size, landholding, livestock, household's assets and number of income sources) and nutrition indicators for the children, either in the N2Africa or in the non-N2Africa groups.

Table 5 Individual dietary diversity score (IDDS) of children 6-59 months in the non-N2Africa group and the N2Africa group in Ghana and in Kenya

\begin{tabular}{|c|c|c|c|c|}
\hline \multirow[t]{2}{*}{ Characteristics } & \multicolumn{2}{|l|}{ Ghana } & \multicolumn{2}{|l|}{ Kenya } \\
\hline & $\begin{array}{l}\text { Non-N2Africa }(n=202)^{\mathrm{a}} \\
\text { Mean }(S D) \text { or } \%\end{array}$ & $\mathrm{~N} 2$ Africa $(n=129)^{\mathrm{a}}$ & Non-N2Africa $(n=154)^{\mathrm{a}}$ & N2Africa $(n=186)^{\mathrm{a}}$ \\
\hline \multicolumn{5}{|l|}{ IDDS (7 food groups, 0 to 7$)^{\mathrm{b}}$} \\
\hline All children & $4.1(1.4)$ & $4.2(1.3)$ & $4.2(0.9)$ & $4.2(1.0)$ \\
\hline children age $6-23$ months & $3.5(1.7)$ & $3.2(1.7)$ & $4.1(0.9)$ & $3.8(1.2)$ \\
\hline children age $24-59$ months & $4.5(0.9)$ & $4.6(0.8)$ & $4.3(0.9)$ & $4.3(0.9)$ \\
\hline Children receiving breastmilk, \% & 42.5 & 38.1 & 24.3 & 22.2 \\
\hline children non-breastfed & $4.4(0.9)$ & $4.6(0.8)$ & $4.2(0.9)$ & $4.3(0.9)$ \\
\hline children breastfed & $3.7(1.7)$ & $3.4(1.6)$ & $4.2(0.8)$ & $3.7(1.1)^{*}$ \\
\hline \multicolumn{5}{|l|}{ Minimum dietary diversity, IDDS $>=4^{\mathrm{c}}$} \\
\hline children age 6-23 months, $\%$ & 65.8 & 60.0 & 76.7 & 62.5 \\
\hline
\end{tabular}

$* P<0.05$ (comparing N2Africa and non-N2Adrica within countries)

${ }^{a}$ See Appendix 1 for sample size per group: children age 6-23 months, children age 24-59 months, children non-breastfed and children breastfed

${ }^{\mathrm{b}}$ IDDS is computed by sum of seven food groups being consumed: 1 . Grains, roots and tubers, 2. Legumes, nuts and seeds, 3. Dairy products, 4. Flesh foods, 5. Eggs, 6. Vitamin A rich fruits and vegetables and 7. Other fruits and vegetables (WHO et al. 2007)

${ }^{\mathrm{c}}$ An individual dietary diversity score of 4 or more in infants and young children reflect a nutrient adequate diet (WHO et al. 2007) 


\subsection{Production-own consumption pathway and income-food purchase pathway}

In Ghana the hypothetical model of the production-own consumption pathway and the income-food purchase pathway was not consistent with the data $\left(X^{2}(\mathrm{df})=62.13(24)\right.$, $P=0.00$ ) (Fig. 2a), while in Kenya the hypothetical model was consistent with the data $\left(X^{2}(\mathrm{df})=22.59(24), P=0.64\right)$ (Fig. 2b). In Ghana, both pathways included non-significant paths. In Kenya, there was only a small positive indirect effect of soybean production on the dietary diversity of children through the production-own consumption pathway, but there was no effect of soybean production on children's dietary diversity through the income-food purchase pathway. The effect of soybean production on the IDDS was very low: a multiplication of individual path coefficients showed that an increase of soybean production by $1 \mathrm{~kg}$ led to an increase of 0.00075 IDDS points. Therefore to have a meaningful effect on children's IDDS an increase in household's soybean production of at least $1000 \mathrm{~kg}$ is needed. Based on soybean production of $800 \mathrm{~kg} / \mathrm{ha}$ after full adoption of N2Africa interventions (Woomer et al. 2014), an increase of $1000 \mathrm{~kg}$ means expansion of 1.2 ha under soybean cultivation. This is highly unlikely, especially in Kenya where the average land size of a household is 1.3 ha. However, children's monthly soybean consumption was not directly related with children's dietary diversity. Household land size was positively related with the production of soybean and total household assets in both models, but mother's education was not related with children's dietary diversity $(P=0.06)$ in the Kenyan model.

In focus group discussions in both Ghana and Kenya, female N2Africa participants more commonly referred to the production-own consumption pathway and males to the income-food purchase pathway with regard to enhanced soybean production. Comparing Ghanaian and Kenyan N2Africa participants, Ghanaian participants referred less to the production-own consumption pathway but rather referred more to the income-food purchase pathway for enhanced production of soybean. In Ghana, few comments were made about soybean consumption and these comments were mixed: 'my children are a bit more healthy because they like to eat soybean' but also 'I have not seen any direct effect of soybean consumption on my health'. By contrast in Kenya, participants were overall positive about soybean consumption: 'it makes children strong', 'soy is so sweet' and 'their health has changed to good health'. In both Ghana and Kenya, participants reported they had received training on soybean processing and learned how to use soya in their local dishes. Further, Ghanaian participants were positive about the soybean market in Northern Ghana ('it gives more money than maize' and 'if your yield is a lot, then you can sell to get money') while Kenyan participants mentioned that there was no market for soybean ('price for soybean is less than for maize' and 'it is difficult to sell soybean'). The remarks on the income-food purchase pathway were not consistent in both countries. The 'extra' income was said to be spent in a wide range of different ways, including 'to pay school fees', 'household items', 'hire people to work on their land', 'buy more food', 'to buy fertilizer', 'to buy seeds', 'for pressing needs' and 'to save for the purchase of a motorbike'. Some farmers mentioned the income was used to buy more food but they did not mention whether they buy nutritious foods and whether this improved their children's diet. Also income was spent on school fees or seeds that theoretically may have an indirect effect on human nutrition, but it remains unclear whether this was the case.

\section{Discussion}

We found no association between participating in this agricultural intervention designed to boost grain legume production and the dietary diversity of children based on a cross-sectional quasi-experimental study. SEM indicated a relatively good fit to the posteriori model in Kenya but not in Ghana, and in Kenya only the production-own consumption pathway for soybean was fully supported, with no effect through the incomefood purchase pathway. Focus group discussions showed that the Ghanaian and Kenyan context of soybean production and consumption differed in the attribution of positive characteristics, variety of local soybean-based dishes, it being a relatively new crop, involvement of women in soybean cultivation, presence of markets, and being treated as a food or cash crop.

\subsection{N2Africa and children's nutrition outcomes}

More households were cultivating grain legumes, especially soybean, in the N2Africa group (100\% in Ghana and in Kenya) than in non-N2Africa group $(88.1 \%$ in Ghana and $94.8 \%$ in Kenya) but we found no differences in total grain legume production among the households cultivating legumes between the two groups in neither Ghana nor Kenya. The absence of differences in grain legume production might be due to weak implementation of the N2Africa intervention in Ghana and weak adoption of N2Africa in Kenya. In Ghana only $60.5 \%$ of participating farmers reported to have received fertilizer and less than half of farmers who received soybean seeds reported they had received inoculant. In Kenya, farmers selected for this study received N2Africa soybean inputs in the short cropping season (from October) in 2010 and/or in long cropping season (from March) in 2011 while the legume production data collected for this study included production from the short cropping season in 2012 and long cropping season in 2013. Therefore the effect of the N2Africa intervention in Kenya on the amount of household legume production depended on the degree of adoption of improved production 
technologies after participating in N2Africa. Adoption may have been restricted as the current availability of rhizobial inoculants in Africa is limited (Ronner et al. 2016), as is the availability and affordability of fertilizers and good quality seeds for rural smallholder farmers. N2Africa participants, both in Ghana and Kenya, reported in the focus group discussions that there was indeed a restricted availability of promoted N2Africa inputs and that fertilizers were too expensive. Contrary to our findings, a previous study conducted across eight countries (including Ghana and Kenya) found that N2Africa participants reported increased grain legume production (Stadler et al. 2016).

We found no differences in children's nutrition outcomes between the non-N2Africa and N2Africa groups in Ghana and Kenya, both not in frequency of consumption of the targeted grain legumes nor in diversity of the diet. Our findings are in line with earlier findings from reviews (Masset et al. 2012; Girard et al. 2012) that suggest there is limited evidence of agricultural interventions having significant positive impacts on child nutrition. Other studies (Berti et al. 2004; Pandey et al. 2016) found that without additional programming in other areas relevant for positive nutrition outcomes, such as gender or nutrition, agricultural programs are unlikely to have a significant positive impact on nutrition. The N2Africa project did include training on soya processing and targeted inclusion of 50\% female participants but during the first phase did not include nutrition-specific training or other genderrelated interventions. Also the fact that we found no differences in legume production between the non-N2Africa and N2Africa group, may explain why we found no difference in children's nutrition outcomes. Furthermore, potential nutrition outcomes resulting from N2Africa may not be sustained from harvest until the end of the lean season, the time data were collected in Ghana and Kenya. Due to the cross-sectional nature of the study, the absence of an association between participation in N2Africa and positive child nutrition outcomes cannot be attributed to a specific cause.

\subsection{Methodological limitations}

Our study suffered from several methodological limitations that hampered our ability to detect an impact of N2Africa on human nutrition (Masset et al. 2012; Girard et al. 2012). Both the lack of detectable increased household legume production and improved children's nutrition outcomes in the N2Africa group compared with the nonN2Africa group, could be due to the limitations related to the cross-sectional quasi-experimental study design we used. Due to the character of the intervention, we could not randomize households to N2Africa or non-N2Africa groups. Absence of randomization may cause differences between treatment groups. To overcome this problem, we matched N2Africa villages with non-N2Africa villages that were under supervision by the same agricultural extension agent in Ghana and we matched N2Africa participants with participants that had recently received N2Africa support but had not yet harvest targeted grain legumes in Kenya. Furthermore, we assumed little spill-over from the N2Africa intervention in our control groups. Comparative studies in four N2Africa countries, including Ghana and Kenya, showed that $60-100 \%$ of the farmers interviewed shared seed of soybean, cowpea and groundnut with others but very few farmers shared the key technologies of the N2Africa intervention, rhizobium inoculants and P-fertilizer (Woomer et al. 2014). The N2Africa and nonN2Africa groups seem comparable as few differences in child's, their mother's and household's characteristics were found at the time of interview and detected differences in characteristics were not associated with children's nutrition outcomes. We also do not have data at a baseline before N2Africa started for these specific villages and cannot rule out potential differences between N2Africa and non-N2Africa households before the intervention. The latent differences between the two groups and the absence of a baseline limited our ability to find differences in household grain legume production and nutrition outcomes between N2Africa and non-N2Africa groups.

In this study dietary diversity was used as a proxy for diet quality, which may also have limitations. IDDS does not differentiate among foods within a food group. This may have two consequences. First, if children already consume grain legumes, the addition of another grain legume to a child's diet will not enhance his or her IDDS even though the added food, in our case soybean, has a better nutrient profile compared with other targeted grain legumes. Adding soybean to the diet therefore may contribute to improved nutrient adequacy of the diet but will not be reflected in an increase of IDDS in this study. However, a recent study among rural Kenyan women showed that food-based scores were only slightly more strongly associated with nutrient adequacy compared with the food group-based scores (Ngala et al. 2015). Second, if children already consume the promoted grain legume, they may consume increased amounts of this grain legume that may contribute to nutrient adequacy yet this will not be reflected in his or her IDDS. A review of dietary diversity studies suggested that scores might be improved by inclusion of portion size requirements (Ruel 2003), however, measuring portion sizes in the field is challenging (Martin-Prevel et al. 2010). Further, in our study grain legume production was selfreported by N2Africa participants (N2Africa group) and head of households (non-N2Africa group), reflecting their previous year's produce for each grain legume individually. Selfreported measures of land size and crop production are known to be inaccurate (Carletto et al. 2013).

In addition to the methodological limitations of the current study, limitations in the design of the N2Africa project itself may have hampered the ability to find differences in children's nutrition outcomes between the N2Africa group and non- 
N2Africa group as well. For a thorough evaluation of the potential nutrition impact of N2Africa, a rigorous monitoring and evaluation system needs to be in place, including indicators along the potential impact pathways towards nutrition outcomes (McDermott et al. 2015; Gelli et al. 2015). For example, no data was available for whether and which crops were replaced by improved varieties of grain legume in the N2Africa intervention, which may affect household's overall crop diversity and the quantity of crops available in the household, and in turn may affect the diet. In case grain legume production replaces part of the maize production it may positively affect the diet while if it replaces all vegetables produced it may negatively affect the diet. Some recent studies show that improved crop diversity is positively related to improved household dietary diversity (Jones et al. 2014) but others show no relation (Rajendran et al. 2014). Limited data on intermediate indicators along the impact pathways hampered the ability to identify explanations for potential impact on nutrition outcomes.

\subsection{Production-own consumption pathway and income-food purchase pathway}

SEM indicated a relatively good fit to the posteriori model in Kenya but not in Ghana. The hypothetical model for Ghana needs improvement. In Kenya we did find an effect through the production-own consumption pathway but not through the income-food purchase pathway. Through the production-own consumption pathway in Kenya, an increase of $1000 \mathrm{~kg}$ of household's soybean production may lead to a modest increase of 0.75 in IDDS. This relative high increase in soybean production is necessary because a small part of the produce may be consumed in the household and from what is consumed within the household little may end up on the plates of children. Differences in five characteristics of the food environment in Ghana compared to Kenya may explain that neither pathway was present in Ghana and only the production-own consumption pathway was present in Kenya.

First, Kenyan N2Africa participants indicated the absence of a good market for soybean while Ghanaian participants indicated there was a relatively good and stable market for soybean compared with maize. Also Kenyan participants indicated that the lack of a nearby soybean market was one of the reasons they decided not to sell their soybean produce. This explains the stronger association between increased soybean production and greater quantity of soybean used for own consumption in Kenya compared with Ghana. In Kenya, soybean was a relatively new crop while in Ghana it has been widely cultivated since the 1990s (in the non-N2Africa group by $18.2 \%$ of households in Kenya versus $75.2 \%$ in Ghana). The better established market for soybean in Ghana may have strengthened the income-food purchase pathway instead of the production-own consumption pathway.
Second, Kenyan N2Africa participant's opinions on the taste and beliefs about potential health benefits from the consumption of soybean were overall more positive compared with those of Ghanaian participants. In Ghana, soybean was mainly consumed in the form of 'dawadawa', similar to a bouillon cube, and thus consumed by all household members in very small amounts. However, in contrast to Ghana, overall fewer grain legumes are consumed by infants and young children in Kenya which leaves more room for increasing the intake of soybean. In addition, Kenyan participants reported a wider variety of local dishes prepared with soybean. These factors may also have led to more soybean production for home consumption in Kenya compared with Ghana.

Third, in Ghana soybean production was weakly associated with the quantity of soybean used for own consumption and strongly with quantity sold, implying soybean was used as a cash crop. This result confirms statistics from the Food and Agriculture Organisation (FAO 2011). Ghanaian N2Africa households cultivated less cowpea but more soybean compared with non-N2Africa households, indicating a possible replacement of cowpea by soybean. As cowpea is mainly used for home consumption, this may suggest that increased soybean production may have led to a reduction of availability of other legume crops for home consumption.

Fourth, enhanced legume production in households where children already consume grain legumes, as in Ghana, may not affect the frequency of legume consumption and/or IDDS but may increase portion sizes consumed. Preliminary analyses from a later survey conducted in Northern Ghana in Karaga district showed that children's daily portion sizes of cowpea, groundnut and soybean (Brouwer et al. unpublished) were associated with household's production of these grain legumes. This suggests that an increase in household's grain legume production may have led to the increased quantity of grain legumes consumed by children in Ghana. As the present study did not include portion sizes in the calculation of IDDS, the potential of the production-own consumption pathway may have been underestimated in Ghana.

Fifth, the proportion of female participants in N2Africa in Kenya was high (above 70\%) compared to Ghana (below $40 \%$ ). A stronger women's decision-making power and control over resources like increased legume production and income from the sale of legume produce, may lead to the channelling of nutritious foods within households to the advantage of children, and to more agricultural income spent on nutritious food and health care for the family, particularly for children (Smith et al. 2003; UNICEF 2011). Female N2Africa participants indeed reported in the focus group discussions more often that the (extra) grain legume produce was used for own consumption, including their children's consumption.

In this study education was used as an indirect measure of women's status while women's status incorporates multiple more direct domains like decision-making-power, mobility 
and attitude towards domestic violence (Lee-Rife 2010; Cunningham et al. 2015). A majority of the mothers of children had not completed any form of education or only completed primary school. The absence of variation in mother's education level may also explain the absence of an association with children's IDDS in our study. Further, household assets were used as an indicator of household income but this may not be representative for total household income including the increased agricultural income.

An agricultural project not designed to be nutrition-sensitive that results in increased availability of a promoted food for home consumption may improve nutrition outcomes, but our findings suggest this depends on the food environment. Based on the focus group discussions and SEM analysis of the productionown consumption and income-food purchase pathways, it appears that a project such as N2Africa has more potential to improve children's dietary diversity through the productionown consumption pathway in a context where (a) farmers attribute positive characteristics towards the targeted nutritious food, (b) a wide variety of local dishes already include the promoted food, (c) women are involved, and d) the targeted food is relatively new and considered as a food crop and not a cash crop. In addition, if there is a strong market available for the promoted food, there is a likelihood that farmers prefer to sell the promoted food instead of keeping it for home consumption. Whether this income is used for improving children's nutrition seems unpredictable or less than expected (Herforth and Ahmed 2015). Thorough understanding of the food environment is therefore necessary to improve the nutrition-sensitivity of agricultural interventions to predict whether boosting legume production may improve the dietary diversity and nutrition outcomes of children.

The cross-sectional quasi-experimental study lacked the methodologically-rigorous design needed to find and draw firm conclusions on associations. In situations where rigorous study designs cannot be implemented or are not part of project evaluation, SEM in a mixed method design is a useful option to analyse whether agriculture projects have the potential to translate in improved nutrition. To our knowledge, our study was the first to use SEM in analysing the theoretical pathways from crop production to improved human nutrition in an explorative way. Further experimental studies are needed to confirm the direction and strength of the identified individual relationships between components within the pathways.

Acknowledgements We thank the Bill and Melinda Gates Foundation for funding this research through the N2Africa project (www.N2Africa. org). We thank the women and caregivers and their husbands or heads of household, extension workers, research assistants and dissemination partners (ACDEP, CSIR-SARI, MoFa and UrbaNet in Ghana; Avene, CIAT-Maseno, Cyeep, Hagonglo, KENFAP, Maseno University, Mfagro, RPK and SSC-VI in Kenya) in Northern Ghana and Western Kenya for their cooperation in data collection. We also thank Gloria Mbera for her assistance in setting up the study design and supervising data collection in Western Kenya.

\section{Compliance with ethical standards}

Conflict of interest The authors declare that they have no conflict of interest.

Open Access This article is distributed under the terms of the Creative Commons Attribution 4.0 International License (http:// creativecommons.org/licenses/by/4.0/), which permits unrestricted use, distribution, and reproduction in any medium, provided you give appropriate credit to the original author(s) and the source, provide a link to the Creative Commons license, and indicate if changes were made.

\section{References}

Barikmo, I., Ouattara, F., \& Oshaug, A. (2004). Food composition table for Mali. TACAM, research series N 9. Oslo: Akershus University College.

Barrios, P. L. (2012). Relationship between household srtucture, maternal autonomy and undernutrition in Brazilian children. New Brunswick, The State University of New Jersey.

Beasley, T. M., \& Schumacker, R. E. (1995). Multiple regression approach to analyzing contingency tables: Post hoc and planned comparison procedures. The Journal of Experimental Education, 64(1), 79-93.

Berti, P. R., Krasevec, J., \& FitzGerald, S. (2004). A review of the effectiveness of agriculture interventions in improving nutrition outcomes. Public Health Nutrition, 7(5), 599-609.

Bezner Kerr, R., Snapp, S., Chirwa, M., Shumba, L., \& Msachi, R. (2007). Participatory research on legume diversification with Malawian smallholder farmers for improved human nutrition and soil feritlity. Experimental Agriculture, 43(04), 437-453.

Bezner Kerr, R., Berti, P. R., \& Shumba, L. (2010). Effects of a participatory agriculture and nutrition education project on child growth in northern Malawi. Public Health Nutrition, 14(08), 1466-1472.

Brouwer, I. D., de Jager, I., Borgonjen, K., Azupogo, F., Rooij, M., Folson, G., et al. (unpublished). Background technical report. Development of food-based recommendations using Optifood Ghana. Washington DC, USA: GAIN.

Carletto, C., Savastano, S., \& Zezza, A. (2013). Fact or artifact: The impact of measurement errors on the farm size-productivity relationship. Journal of Development Economics, 103, 254-261.

Cogill, B. (2003). Anthropometric indicators measurement guide. Washington DC, USA: Food and nutrition technical assistance (FANTA) project, FHI 360.

Creswell, J. W., \& Plano Clark, V. L. (2011). Designing and conducting mixed methods research. California: SAGE Publications.

Cunningham, K., Ruel, M., Ferguson, E., \& Uauy, R. (2015). Women's empowerment and child nutritional status in South Asia: A synthesis of the literature. Maternal \& Child Nutrition, 11(1), 1-19.

Du, L., Pinga, V., Klein, A., \& Danton, H. (2015). Leveraging agriculture for nutrition impact through the feed the future initiative. Advances in Food and Nutrition Research, 74, 1-46.

FAO. (2010). Guidelines for measuring household and individual dietary diversity. Rome: FAO.

FAO. (2011). FAOSTAT: Food balance sheet. Rome: FAO.

FAO, INFOODS, ECOWAS/WAHO, \& Bioversity International. (2012). West African food composition table. Rome: FAO.

Franke, A. C., Rufino, M. C., \& Farrow, A. (2011). Characterisation of the impact zones and mandate areas in the N2Africa project. Wageningen: N2Africa.

Garson, G. D. (2015). Structural Equation Modeling (blue book series). Asheboro: Statistical Associates Publishing.

Gelli, A., Hawkes, C., Donovan, J., Harris, J., Allen, S. L., de Brauw, A., et al. (2015). Value chains and nutrition: A framework to support the 
identification, design, and evaluation of interventions. (Vol. discussion paper 01413). Washington DC, USA: IFPRI.

Gibson, R. S., \& Ferguson, E. L. (2008). An interactive 24-hour recall for assessing the adequacy of iron and zinc intakes in developing countries. In HarvestPlus technical monograph 8. Washington DC, USA \& Cali: IFPRI \& CIAT.

Giller, K. E., Franke, A. C., Abaidoo, R., Baijukya, F. P., Bala, A., Boahen, S., et al. (2013). N2Africa: Putting nitrogen fixation to work for smallholder farmers in Africa. In B. Vanlauwe, P. van Asten, \& G. Blomme (Eds.), Agro-ecological intensification of agricultural Systems in the African Highlands (pp. 156-174). London: Routledge.

Girard, A. W., Self, J. L., McAuliffe, C., \& Olude, O. (2012). The effects of household food production strategies on the health and nutrition outcomes of women and young children: A systematic review. Paediatric and Perinatal Epidemiology, 26(Suppl 1), 205-222.

Herforth, A., \& Ahmed, S. (2015). The food environment, its effects on dietary consumption, and potential for measurement within agriculture-nutrition interventions. Food Security, 7(3), 505-520.

Herforth, A., \& Harris, J. (2014). Understanding and applying primary pathways and principles. Brief 1: Improving nutrition through agriculture. Arlington, USA: USAID/strengthening partnerships, results, and innovations in nutrition globally (SPRING) project.

Hoddinott, J. (2011). Agriculture, health, and nutrition: Toward conceptualizing the linkages. Washington DC: IFPRI.

de Jager, I. (2013). Nutritional benefits of legume consumption at household level in rural areas of sub-Saharan Africa. Background document. Wageningen, The Netherlands: N2Africa.

Jahnke, H. E. (1982). Livestock production systems and livestock development in tropical Africa. Kiel: Vauk.

Jones, A. D., Shrinivas, A., \& Bezner-Kerr, R. (2014). Farm production diversity is associated with greater household dietary diversity in Malawi: Findings from nationally representative data. Food Policy, 46, 1-12.

Keats, S., \& Wiggins, S. (2014). Future diets: Implications for agriculture and food prices. London: ODI.

Kennedy, G. L., Pedro, M. R., Seghieri, C., Nantel, G., \& Brouwer, I. (2007). Dietary diversity score is a useful indicator of micronutrient intake in non-breast-feeding Filipino children. The Journal of Nutrition, 137(2), 472-477.

Lee-Rife, S. M. (2010). Women's empowerment and reproductive experiences over the lifecourse. Social Science and Medicine, 71(3), 634-642.

Lukmanji, Z., Hertzmark, E., Mlingi, N., Assey, V., Ndossi, G., \& Fawzi, W. (2008). Tanzania food composition tables. Dar es Salaam, Tanzania: MUHAS, TFNC, HSPH.

Malapit, H. J. L., \& Quisumbing, A. R. (2015). What dimensions of women's empowerment in agriculture matter for nutrition in Ghana? Food Policy, 52, 54-63.

Martin-Prevel, Y., Becquey, E., \& Arimond, M. (2010). Food group diversity indicators derived from qualitative list-based questionnaire misreported some foods compared to same indicators derived from quantitative 24-hour recall in urban Burkina Faso. The Journal of Nutrition, 140(11), 2086s-2093s.

Masset, E., Haddad, L., Cornelius, A., \& Isaza-Castro, J. (2012). Effectiveness of agricultural interventions that aim to improve nutritional status of children: Systematic review. The British Medical Journal, 344, d8222.

Mather, D., Donocan, C., \& Boughton, D. (2009). Measuring the impact of public and private assets on household crop income in rural Mozambique: 2002-2005. Michigan State, Michigan State University.

McDermott, J., Johnson, N., Kadiyala, S., Kennedy, G., \& Wyatt, A. J. (2015). Agricultural research for nutrition outcomes-rethinking the agenda. Food Security, 7(3), 593-607.

Menon, P., Rawat, R., \& Ruel, M. (2013). Bringing rigor to evaluations of large-scale programs to improve infant and young child feeding and nutrition: The evaluation designs for the Alive \& Thrive initiative. Food and Nutrition Bulletin, 34(3 Suppl), S195-S211.
Monteiro, C. A. (2009). The decline in child malnutrition in Brazil. Cadernos de Saúde Pública, 25, 950-950.

Moursi, M. M., Arimond, M., Dewey, K. G., Trèche, S., Ruel, M. T., \& Delpeuch, F. (2008). Dietary diversity is a good predictor of the micronutrient density of the diet of 6- to 23month-old children in Madagascar. The Journal of Nutrition, $138,2448-2453$.

Muhammad, A., Seale, J. L., Meade, B., \& Regmi, A. (2011). International evidence on food consumption patterns $A n$ Update Using 2005 International Comparison Program Data. Tb-1929. USA: USDA, Economic Research Service.

Muthayya, S., Rah, J. H., Sugimoto, J. D., Roos, F. F., Kraemer, K., \& Black, R. E. (2013). The global hidden hunger indices and maps: An advocacy tool for action. PloS One, 8(6), e67860.

Ngala, S. A. (2015). Evaluation of dietary diversity scores to assess nutrient adequacy among rural Kenyan women. Wageningen University, Wageningen, The Netherlands.

Pandey, V. L., Mahendra Dev, S., \& Jayachandran, U. (2016). Impact of agricultural interventions on the nutritional status in South Asia: A review. Food Policy, 62, 28-40.

Pinstrup-Andersen, P. (2012). The food system and its interaction with human health and nutrition. In Reshaping agriculture for nutrition and health: An IFPRI 2020 book (pp. 21-29). Washington DC: IFPRI.

Rajendran, S., Afari-Sefa, V., Bekunda, M., Dominick, I., \& Lukumay, P. J. (2014). Does crop diversity contribute to dietary diversity? Evidence from integration of vegetables into maize based farming systems in Tanzania. Paper presented at the 88th Anual Conference, Paris, France.

Ronner, E., Franke, A. C., Vanlauwe, B., Dianda, M., Edeh, E., Ukem, B., et al. (2016). Understanding variability in soybean yield and response to P-fertilizer and rhizobium inoculants on farmers' fields in northern Nigeria. Field Crops Research, 186, 133-145.

Ruel, M. T. (2003). Operationalizing dietary diversity: A review of measurement issues and research priorities. The Journal of Nutrition, 133(11), 3911S-3926S.

Ruel, M. T., \& Alderman, H. (2013). Nutrition-sensitive interventions and programmes: How can they help to accelerate progress in improving maternal and child nutrition? The Lancet, 382, 536-551.

Smith, L. C., Ramakrishnam, U., Ndiaye, A., Haddad, L., \& Martorell, R. (2003). The importance of women's status for child nutrition in developing countries. In IFPRI research report 131. Washington DC: IFPRI.

Stadler, M., van den Brand, G. J., \& Ronner, E. (2016). N2Africa early impact survey, phase I. Progress document. Wageningen, The Netherlands: N2Africa.

Swinburn, B., Kraak, V., Rutter, H., Vandevijvere, S., Lobstein, T., Sacks, G., et al. (2015). Strengthening of accountability systems to create healthy food environments and reduce global obesity. The Lancet, 385(9986), 2534-2545.

UN. (2005). Designing household survey samples: Practical guidelines. New York: UN DESA.

UNICEF. (2011). Gender influences on child survival, health, and nutrition: A narrative review. New York: UNICEF.

UNICEF, WHO, \& World Bank Group (2015). Levels and trends in child malnutrition. UNICEF - WHO - World Bank Group joint child malnutrition estimates. USA: UNICEF, WHO \& World Bank Group.

WHO (2011). WHO Child Growth Standards: SPSS syntax file. http://www.who.int/childgrowth/software/en/. Accessed 23 August 2016.

WHO Multicentre Growth Reference Study Group. (2006). WHO child growth standards: Length/height-for-age, weight-forage, weight-for-length, weight-for-height and body mass index-for-age: Methods and developments. Geneva: World Health Organization. 
WHO, UNICEF, USAID, AED, UCDAVIS, \& IFPRI. (2007). Indicators for assessing infant and young child feeding practices. In Conclusions of a consensus meeting held 6-8 November 2007 in Washington DC, USA. Geneva: WHO.

Woomer, P. L., Huising, J., Giller, K. E., Baijukya, F. P., Kantengwa, S., Vanlauwe, B., et al. (2014). N2Africa: Final Report of the first Phase - 2009 - 2013. Wageningen: N2Africa.

Working Group on Infant and Young Child Feeding Indicators. (2007). Developing and validating simple indicators of dietary quality of infants and young children in developing countries Additional analysis of 10 data sets. Washington DC: USAID.

World Bank. (2007). From agriculture to nutrition: Pathways, synergies, and outcomes. Washington DC: The International Bank for Reconstruction and Development / The World Bank.

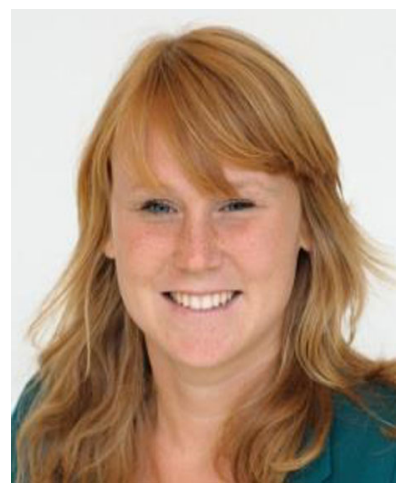

Ilse de Jager is a $\mathrm{PhD}$ candidate at the Division of Human Nutrition and the Plant Production Systems group at Wageningen University, the Netherlands. She started her PhD research in 2014 after obtaining her MSc degree in Human Nutrition. Her research focuses on impacts of agriculture on improving diets and nutritional status of vulnerable groups from rural households in sub-Saharan Africa, in particular focusing on the potential of grain legumes. She conducts her $\mathrm{PhD}$ research within the context of the agricultural development project N2Africa (www.N2Africa.org) that was one of the winning projects of the 2013 Harvesting Nutrition Contest initiated by the World Bank.

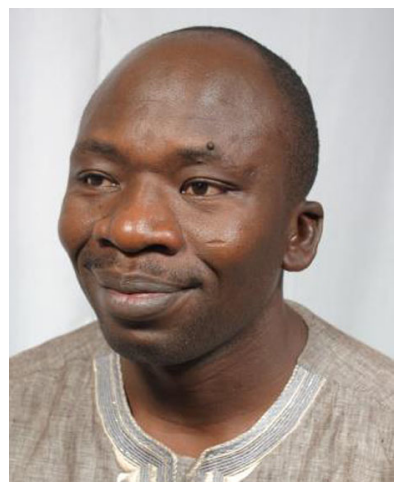

Abdul-Razak Abizari is a trained Public Health Nutritionist and a Senior Lecturer in the School of Allied Health Sciences of the University for Development Studies, Ghana, where he has been a member of faculty since 2005 . He has vast experience in both basic and applied research in nutrition and allied fields. Dr. Abizari has been involved in large collaborative research projects with funding support from UNICEF, IFPRI, USAID, GAIN, CIDA, Nestle Foundation for Nutrition Research and Wageningen University since 2001. His research interests include micronutrient nutrition, school feeding, food and nutrition security, dietary assessment, and maternal, infant and young child nutrition.

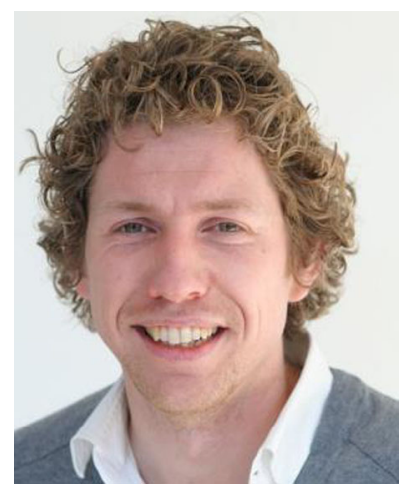

Jacob C. Douma is a quantitative ecologist in the Centre for Crop Systems Analysis and the Laboratory of Entomology at Wageningen University. He is interested in how plant-plant interactions are shaped by insects, and how plant communities are assembled. He wants to unravel these processes and relationships through the application of (statistical) models, field and greenhouse experiments and the analysis of large datasets.

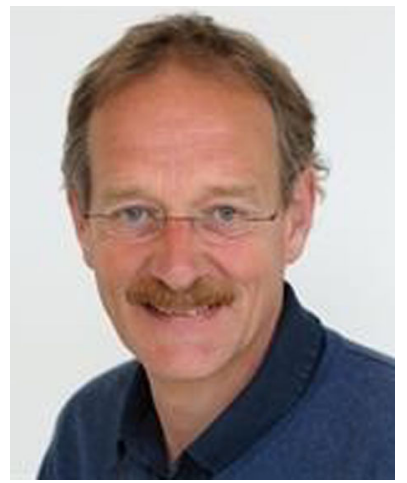

Ken E. Giller is Professor of Plant Production Systems at Wageningen University. He leads a group of scientists with profound experience in (farming) systems analysis and exploring future scenarios of change. Ken's research has focused on smallholder farming systems in subSaharan Africa, and in particular problems of soil fertility and the role of nitrogen fixation in tropical legumes. He is author of the book "Nitrogen Fixation in Tropical Cropping Systems".

Ken joined Wageningen University in 2001 after holding professorships at Wye College, University of London, and the University of Zimbabwe.

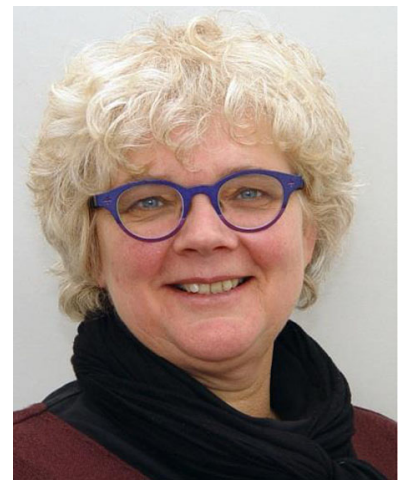

Inge D. Brouwer is Associate Professor at the Division of Human Nutrition, Wageningen University. Her research focuses on the improvement of dietary quality of (young) women and children in low and middle income countries through agricultural or food systems approaches, with special emphasis on micronutrient deficiencies. Dr. Brouwer has acquired many research funds from food industries, national funding programmes as well as from EU FP6 and FP7 Framework Programmes. She coordinated a large FP7 research programme INSTAPA focusing on improvement of nutrition through enhancing staple crops (sorghum, millet, maize and cassava) in Africa through biofortification, fortification and post-harvest processing involving over 40 scientists from European and African countries. At the moment she is involved in development of the Food Systems for Healthier Diets research programme in collaboration with CGIAR research institutes. 